\title{
To Share or Not to Share? Capacity Reservation in a Shared Supplier
}

\author{
Anyan $\mathrm{Qi}^{*}$ (D) \\ Naveen Jindal School of Management, The University of Texas at Dallas, Richardson, Texas 75080, USA, axq140430@utdallas.edu
}

Hyun-Soo Ahn

Stephen M. Ross School of Business, University of Michigan, Ann Arbor, Michigan 48109, USA, hsahn@umich.edu

\author{
Amitabh Sinha \\ Amazon, Seattle, Washington 98109, USA, amitabsi@amazon.com
}

\begin{abstract}
W hen a supplier serves multiple buyers, the buyers often reserve the supplier's capacity in advance to secure the supply to fulfill their demand. In this study, we analyze two common types of capacity reservation: exclusive and first-priority reservations. Both reservations give a buyer first access to its reserved capacity, but the reservations differ in how the leftovers (if any) are used. In most cases, as long as the buyer gets to use the reserved capacity first, it does not pay attention to how the leftover capacity is utilized, leaving that to the supplier's discretion (first-priority). However, in a number of cases, buyers prohibit discretionary use of the reserved capacity ("no one touches my leftovers") and implement the restriction by placing an employee at the supplier or installing monitoring devices (exclusive). One potential benefit of first-priority capacity is resource pooling: allowing access to one another's leftovers can reduce the amount of capacity reserved by the buyers while enabling the supplier to satisfy buyers' orders better in some cases. The Operations Management literature suggests that the benefit of resource pooling is greater when the demand correlation is negative and smaller when the correlation is positive. We investigate the capacity reservation type and level that each buyer chooses facing uncertain (and correlated) demand. We investigate how the reservation price and demand correlation affect the equilibrium outcome. We also examine the supplier's decision to set the optimal reservation prices. We find that at least one firm reserves first-priority capacity in equilibrium as long as the supplier offers a discount for first-priority capacity (or charges a premium for exclusive capacity). Depending on the reservation price difference and demand correlation, we find that the equilibrium outcome is inefficient (i.e., not Pareto optimal) for the buyers when they settle in a free-rider or a prisoner's dilemma equilibrium. We show that the supplier always induces both buyers to reserve a large amount of exclusive capacity so that the supplier can make profits from both capacity reservation and production. While this seems like the best scenario for the supplier, we show that, allowing bilateral capacity transfer (e.g., the buyers trading their reserved capacity) can improve not only the buyers' profits but also the supplier's profit.
\end{abstract}

Key words: capacity reservation; exclusive capacity; first-priority capacity; transferrable capacity; demand correlation History: Received: July 2018; Accepted: June 2019 by Haresh Gurnani, after 2 revisions.

\section{Introduction}

When multiple firms procure from the same supplier, a significant risk is capacity shortage. To secure enough supply, many buying firms reserve capacity before demands are realized by paying a fee. Once the demand is realized, buying firms have the first right to use the reserved capacity. In many cases, buying firms do not manage or control their unused reserved capacity, leaving the usage of the leftovers to the supplier's discretion (first-priority capacity). According to the Global Supply Chain Director at a leading agricultural supply firm, the company routinely pays to reserve capacity of its key ingredient suppliers. As long as the suppliers fulfill the orders, the firm does not restrict how the unused capacity is used by its suppliers. Roels and Tang (2017) consider a similar situation where the reserved capacity if not utilized can be used to serve the demand of another firm.

In some cases, however, the reserved capacity is exclusively tied to the buying firm, excluding any discretionary use by the supplier (exclusive capacity). One major buyer of Cosmax ${ }^{1}$ exclusively reserved capacity of filling machines at the supplier. The exclusivity was enforced using proprietary molds and monitoring devices (counters). Thus, the buyer is able to monitor the machine's utilization. The exclusivity can also be implemented, for example, by a buying firm's employee residing in the supplier's factory (e.g., Cisco).

While both first-priority and exclusive capacity reservations guarantee the first right to access the 
reserved capacity to the buying firms, the feasibility of using the leftovers affects the total available capacity of the supplier as well as that of the buying firms.

One apparent benefit of first-priority capacity is that it allows the supplier to pool the uncertain demands of the buying firms and increase total capacity usage. For the same total capacity, first-priority reservation allows the supplier to produce more than exclusive reservation through demand pooling. The Operations Management (OM) literature has shown that the benefit of pooling is larger when demands are uncorrelated or negatively correlated than when they are positively correlated (Simchi-Levi et al. 2008), and variability pooling has become one of the most popular OM practices. However, in a supply chain where each buying firm pays to reserve capacity, pooling production resources may not always benefit the supplier. To see this, consider the case where both buying firms know they can access the other's leftover capacity. Knowing that they can potentially access the other firm's capacity when their demand is high, the firms may decide to reserve less, which then reduces the total capacity and the supplier's profit. If this happens, the supplier no longer benefits much from the pooled resources. On the other hand, although the supplier cannot pool the resources under exclusive capacity, exclusivity can induce both buyers to reserve more capacity, potentially resulting in a higher profit for the supplier. Therefore, the benefit of pooling through first-priority reservation is no longer trivial when multiple firms reserve capacity, and its advantage over exclusive reservation depends not only on the difference in the capacity reservation prices (e.g., the premium to reserve capacity exclusively) but also on demand correlation, as both factors together affect the reservation type and level that each buyer chooses.

In this study, we investigate capacity reservation in a supply chain with multiple buyers. Specifically, our research questions are as follows: (i) Which types of capacity will buying firms reserve and what are the corresponding capacity levels? (ii) How does the demand correlation drive the firms' capacity reservation decisions? (iii) Under which type of capacity reservation does the supplier benefit more? (iv) If inefficiency arises due to under-reservation or overreservation, how should the capacity reservation practice be adjusted to improve efficiency?

We examine these questions in a non-cooperative game with one supplier supplying to two buying firms. In this game, each firm, facing uncertain demand, decides the capacity reservation type-between exclusive and first-priority reservations - and the capacity reservation level. Then, demands are realized and fulfilled according to the contractual term of the reserved capacity. We characterize conditions (as a function of the reservation price and demand correlation) under which each of three equilibria emerges: both firms reserving a large amount of exclusive capacity, both firms reserving first-priority capacity, and one firm reserving exclusive capacity and the other reserving first-priority capacity. In the latter two equilibria (with both firms or only one firm reserving first-priority capacity), we show that the reservation level explicitly depends on the reservation prices and demand correlation. As the price of reserving exclusive capacity increases, the equilibrium changes from both reserving exclusive capacity, to only one firm reserving exclusive capacity, to neither firm reserving exclusive capacity. Interestingly, we find that, if a small premium for exclusive capacity is imposed, one firm chooses the more expensive exclusive capacity while the other firm chooses the first-priority capacity. Reserving the more expensive exclusive capacity forces the other firm to build a larger capacity, and pays off when the firm's demand is high as the firm can tap into the other firm's leftover capacity. We also investigate how the equilibrium regime changes as demand correlation changes.

We find that the buying firms can be hurt in equilibrium in two ways. In the first case, both firms are trapped in a prisoner's dilemma, where they reserve a large amount of exclusive capacity even when the reservation prices are the same for both types. In the second case, a free-rider equilibrium, where one firm allows the other to free-ride on its capacity, can arise. In both cases, the total profit of both firms could have increased had they both chosen first-priority capacity and benefited from the pooled capacity. As demand correlation becomes sufficiently high, both adverse outcomes vanish because buyers benefit less from capacity pooling.

We then extend the model to include the situation where the supplier decides the capacity reservation prices. Interestingly, we find that, in equilibrium, the supplier will always choose reservation prices such that both firms will be induced to reserve a large amount of exclusive capacity. This means that, offering a discount in exchange for the freedom to use the leftover capacity (or charging a premium for exclusive reservation) does not benefit the supplier. While inducing buying firms to reserve a large exclusive capacity seems best for the supplier, we show that the supplier can charge an even higher reservation price if the buyers are able to transfer their reserved capacity with a fee. We show that, under certain conditions, allowing capacity transfer with a fee between the buying firms is Pareto-improving and increases the profit of all parties. We show that such a win-winwin outcome can occur when demand correlation is low. Finally, we numerically show that our main results and insights hold for other demand models. 
The rest of the study is organized as follows. We review the relevant literature in section 2 . Then we analyze the base model in section 3 and derive the supplier's equilibrium capacity reservation prices in section 4 . We then consider the transferrable capacity reservation in section 5 . We conduct a final check of the robustness of the analytical findings by numerical study in section 6 before concluding in section 7 .

\section{Literature Review}

Our work is one of the first papers to combine sourcing from a shared supplier and capacity reservation. Nevertheless, our contributions are best understood in light of the findings of the papers on a supply network with shared suppliers and capacity management. We review the related literature from both strands of work below.

Our work is closely related to the outsourcing literature. Earlier work focuses on analyzing the relationship between one buyer and one supplier, as, for example, in Iyer et al. (2005), Zhu et al. (2007) and Babich (2010). In more recent years, the focus has moved toward more complicated relationships, to include dual sourcing (Li 2013, Li and Wan 2016, Wang et al. 2010) and a back-up supplier (Yang et al. 2009). Papers in the setting where firms outsource to a common supplier cover issues including economy of scale (Cachon and Harker 2002), strategic use of sourcing from a high cost supplier (Arya et al. 2008), supplier's reliability (Wadecki et al. 2012), knowledge spillover (Wang et al. 2014), and vertical integration and supplier development (Jin et al. 2019). All of these papers explore different incentives to outsource, identify possible adverse outcomes as a result of outsourcing, and find ways to coordinate misaligned incentives using either a noncooperative or cooperative game framework. Most papers that examine multiple firms outsourcing to a common supplier do not consider a capacity constraint. Discussions related to capacity management in an outsourcing setting are relatively sparse.

Capacity management (within a firm) has been studied in the industrial organization and operations management literature for decades, with Dixit (1980) being an example of an early and influential paper in this area. Van Mieghem (2003) and Wu et al. (2005) provide reviews of earlier work. More recent papers in capacity investment within the firm or in an outsourcing setting cover issues on competing firms' choice of flexible or dedicated technology (Goyal and Netessine 2007), the impact of contract manufacturing on innovation and capacity investment (Plambeck and Taylor 2005, 2007), timing of market entry (Ülkü et al. 2005), demand forecast accuracy and investment responsibility (Ülkü et al. 2007), and competing firms' investment in a shared supplier (Qi et al. 2015).
Qi et al. (2015) consider a similar supply chain structure with two buying firms sharing a common supplier; their work focuses on the competition between the firms facing non-linear capacity investment costs and deterministic demand. The focus of the study is to examine how much capacity each firm will build for given its capacity type and the competitor's type. On the other hand, our study examines both the capacity reservation type and level that both firms choose given stochastic demand and demand correlation. These two papers complement each other and further our understanding of shared capacity.

A few recent papers address capacity reservation issues in an outsourcing setting with multiple buying firms. Roels and Tang (2017) consider a bidirectional alliance between two firms with exogenously endowed capacity. The firms make their capacity reservation and/or capacity transfer pricing decisions under $e x$ ogenously given contract types. Each firm's production requires one unit of capacity by each firm, and therefore the (endowed) capacities are strategic complements for production. The focus of the firm is a bilateral capacity exchange between the two buying firms. In contrast, we consider a supply network with two buying firms sharing a common supplier where the supplier's capacity is installed upon the capacity reservation decisions by the buying firms. In our setting, each firm chooses their contract types to reserve capacity. Each firm's production requires one unit of the supplier's capacity (whether it is reserved by the firm itself or by the other firm if the contract allows such access), and therefore the (reserved) capacities by the two firms are strategic substitutes in nature. These differences make the results and insights different in their work and ours.

Kemahlığlu-Ziya (2015) consider the contract of two firms with a manufacturer for capacity reservation and wholesale prices. They can renegotiate the contracts after demand realization, allowing the firms to use more or less capacity than what was contracted. They show that a firm with a weaker buyer power (who was not able to negotiate a low wholesale price upfront) may benefit more from renegotiation than a stronger firm. Li et al. (2011) compare three capacity reservation options: no-transfer, suppliertransfer, and buyer-transfer, depending on whether the reserved capacity can be accessed by other firms and whether it is costly to access the other firm's reserved capacity. They identify which option is optimal from the supplier's perspective. In contrast with these two papers, our work differs (among other minor points) in that neither of the papers consider the situation where buying firms can endogenously restrict how the reserved capacity should be used by the supplier. This feature together with demand correlation allows us to derive managerial insights 
regarding the practices in using the different reservation contracts.

\section{Base Model}

We consider a model with a single supplier and two buying firms who sell products at price $p$. We use $i=1,2$ to index the two (buying) firms, and $s$ to denote the supplier. At the beginning of the game, each firm selects a type of capacity reservation. Then, each firm selects the capacity reservation level and pays the reservation fee before demand realization. After each firm reserves capacity, the demands are realized, and each firm places an order (at the unit wholesale price $w$ ) to fulfill its demand using the supplier's capacity.

We consider two reservation types. Under the exclusive (denoted by $e$ ) reservation, the buying firm exclusively uses the reserved capacity and prohibits the usage of any leftover capacity for the other firm. Under the first-priority reservation (denoted by $f$ ), the buying firm has the first priority to use the capacity, but leaves the usage of leftover capacity to the supplier's discretion. The combination of reserved capacity type and level together with the realized demands determines the amount of capacity that firms can tap into. For instance, if both firms choose exclusive reservation, each firm can produce only up to its own reserved capacity. On the other hand, if both firms choose firstpriority reservation, each firm can use its own reserved capacity plus the leftover capacity of the other firm.

Let $c_{e}$ and $c_{f}$ be the unit price to reserve exclusive and first-priority capacity, respectively. Hence, if firm $i$ chooses to reserve $k_{i}$ units of capacity with type $\tau_{i} \in\{e, f\}$, the total cost is $c_{\tau_{i}} k_{i}$. We assume that exclusive reservation is more costly than first-priority reservation $\left(c_{e} \geq c_{f}\right)$. This assumption is reasonable, since the supplier can use the leftovers of first-priority capacity to fulfill other orders, but must waste any leftover capacity under exclusive capacity. ${ }^{2}$ We note, however, that our analysis and derivation do not require that $c_{e} \geq c_{f}$.

To model a firm's profit function, let $D_{i}$ be the random variable representing the uncertain demand of firm $i$. Then, for given capacity reservation levels $\left(k_{1}, k_{2}\right)$, firm $i$ 's expected profit function under capacity type $\left(\tau_{1}, \tau_{2}\right)$ is as follows,

$$
\begin{aligned}
\pi_{i}^{\tau_{1} \tau_{2}}\left(k_{1}, k_{2}\right)= & (p-w) E\left[\min \left\{D_{i}, k_{i}+\left(k_{j}-D_{j}\right)^{+} 1_{\left\{\tau_{j}=f\right\}}\right\}\right] \\
& -c_{\tau_{i}} k_{i}, \text { for } i, j \in\{1,2\} \text { and } i \neq j .
\end{aligned}
$$

Note that $\mathbb{1}_{\{C\}}=1$ if condition $C$ is satisfied, and 0 otherwise, and $X^{+} \triangleq \max \{X, 0\}$.

From this, the equilibrium capacity reservation levels, $\left(k_{1}^{\tau_{1} \tau_{2}}, k_{2}^{\tau_{1} \tau_{2}}\right)$, satisfy the following system of equations simultaneously:

$$
\begin{aligned}
& k_{1}^{\tau_{1} \tau_{2}}=\arg \max _{k_{1} \geq 0}\left\{\pi_{1}^{\tau_{1} \tau_{2}}\left(k_{1}, k_{2}^{\tau_{1} \tau_{2}}\right)\right\} ; \\
& k_{2}^{\tau_{1} \tau_{2}}=\arg \max _{k_{2} \geq 0}\left\{\pi_{2}^{\tau_{1} \tau_{2}}\left(k_{1}^{\tau_{1} \tau_{2}}, k_{2}\right)\right\} .
\end{aligned}
$$

From Equation (2), we can recast the problem to choose the capacity reservation types as a $2 \times 2$ reduced form game with the following payoff matrix in which $\Pi_{i}^{\tau_{1} \tau_{2}}$ represents the sub-game perfect expected profit, that is, $\Pi_{i}^{\tau_{1} \tau_{2}} \triangleq \pi_{i}^{\tau_{1} \tau_{2}}\left(k_{1}^{\tau_{1} \tau_{2}}, k_{2}^{\tau_{1} \tau_{2}}\right)$.

\begin{tabular}{lcc}
\hline$\left(\tau_{1}, \tau_{2}\right)$ & $e$ (exclusive) & $f($ first-priority) \\
\hline$e$ (exclusive) & $\Pi_{1}^{e e}, \Pi_{2}^{e e}$ & $\Pi_{1}^{e f}, \Pi_{2}^{e f}$ \\
$f$ (first-priority) & $\Pi_{1}^{f e}, \Pi_{2}^{\text {fe }}$ & $\Pi_{1}^{f f}, \Pi_{2}^{f t}$ \\
\hline
\end{tabular}

One of the central research questions is how demand correlation affects the type and level of capacity reservation. As the literature on pooling suggests, the utilization of pooled resources is greater when demands are negatively correlated because the fact that one firm's demand is high (hence, more capacity is needed) implies that the other firm's demand is low (hence, it is more likely to have leftover capacity). Therefore, even when the marginal demand distribution remains unchanged, the capacity type and level that a buyer prefers may change depending on the demand correlation. To derive the results and insights analytically (sections 3-5), we consider the following demand distribution for $D_{i}$. Following the literature, e.g., Roels and Tang (2017), we assume all the cost and price parameters as well as the demand distributions are public information.

We consider that $D_{i}$ is identically distributed and follows a marginal distribution with the realized value of $H$ of probability $\alpha$ and $L$ of probability $1-\alpha$, and we use $\beta$ to denote the conditional probability of firm i's demand being $H$ given that firm $j$ 's demand is also $H$. Note that by changing $\beta$ while fixing $\alpha$, we are able to change the demand correlation without changing the marginal distribution of $D_{i}$. We establish the relationship between the demand correlation $\rho$ and the condition probability $\beta$ in the following lemma. All proofs are relegated to the appendix.

Lemma 1. (Joint Demand Distribution and Demand Correlation). Let $\operatorname{Pr}\left(D_{i}=H\right)=\alpha$ and $\operatorname{Pr}\left(D_{i}=H\right.$ $\left.D_{j}=H\right)=\beta, i, j \in\{1,2\}, i \neq j$.

(i) The joint distribution of demands, $\left(D_{i}, D_{j}\right)$, is as follows.

$$
\begin{aligned}
\operatorname{Pr}\left(D_{i}=H, D_{j}=H\right) & =\beta \alpha, \\
\operatorname{Pr}\left(D_{i}=H, D_{j}=L\right) & =\operatorname{Pr}\left(D_{i}=L, D_{j}=H\right) \\
& =(1-\beta) \alpha, \\
\operatorname{Pr}\left(D_{i}=L, D_{j}=L\right) & =1-2 \alpha+\alpha \beta .
\end{aligned}
$$


(ii) The demand correlation $\rho$ is a linear function of the conditional probability $\beta$ :

$$
\rho=\frac{\beta-\alpha}{1-\alpha}
$$

(iii) As $\beta$ increases, ceteris paribus, the demand correlation increases while the marginal distribution remains unchanged. Consider the range of $\beta$ under which the joint distribution is well-defined. The corresponding range for the demand correlation $\rho$ is $\left[\frac{-\alpha}{1-\alpha}, 1\right]$ when $\alpha \in\left[0, \frac{1}{2}\right) ;$ and $\left[\frac{\alpha-1}{\alpha}, 1\right]$ when $\alpha \in\left[\frac{1}{2}, 1\right]$.

Note that the demand model above allows us to isolate the effect of demand correlation without losing analytical tractability. The feasible region of the demand correlation with respect to the marginal distribution $\alpha$ is shown in Figure 1. Note that the perfectly negative correlation of -1 can occur only when the marginal distribution is symmetric, that is, $\alpha=\frac{1}{2}$. When the marginal distribution is not symmetric, negative correlation is possible, but the lowest correlation for a given marginal distribution is greater than -1 . Note that our marginal demand distribution (two-point demand distribution) is known as the "boom-bust" distribution and has been used extensively to model demand in the $\mathrm{OM}$ and marketing literature (e.g., Taylor and Plambeck 2007). Alternatively, one might consider using a bivariate normal distribution with correlation. We show that while most results continued to hold under the bivariate normal distributions (as shown in section 6), deriving

Figure 1 Feasible Region of Demand Correlation $\rho$ with Respect to the Marginal Distribution $\alpha$ When the Marginal Demand Distributions of the Two Buyers are Identical [Color figure can be viewed at wileyonlinelibrary.com]

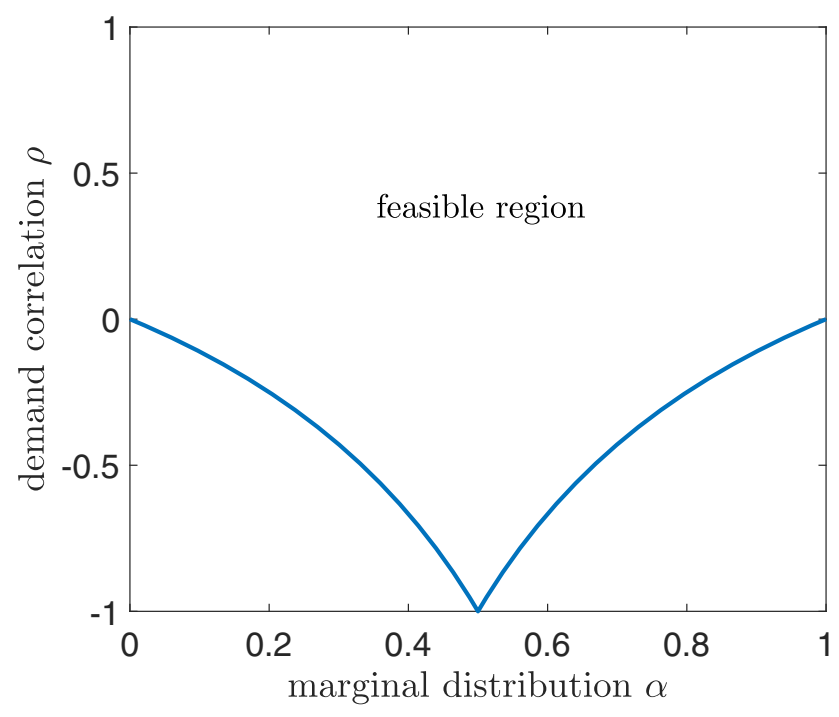

clean analytic results is still challenging with such a distribution.

The linear relationship between the demand correlation $\rho$ and the conditional probability $\beta$ in Equation (3) allows us to easily capture the impact of demand correlation by analyzing the impact of the conditional probability $\beta$. For convenience of exposition, we refer to $\beta$ as "proxy demand correlation" in the following analysis.

Note that we do not explicitly model whether the two firms are competing or not. Instead, we capture the impact of the relationship between the firms on their capacity reservation at the supplier through demand correlation. For instance, if the two firms face independent demands, then the correlation is zero. If the two firms compete in a zero-sum game, the correlation is -1 .

In what follows, we first analyze the equilibrium capacity reservation levels for given capacity reservation type choices by both firms in section 3.1, and then characterize the equilibrium capacity type choices in section 3.2.

\subsection{Capacity Reservation Levels}

Before we present our results, it should be noted that we (implicitly) assume that the marginal cost to reserve one unit of capacity is less than the expected marginal profit to satisfy one unit of demand, that is, $c_{\tau_{i}} \leq(p-w) \alpha$. Otherwise, it is trivial to show that the firms will only reserve a capacity level equal to or less than the lower bound $L$ (note that the firm will not reserve any capacity if the capacity reservation cost is higher than the profit margin, that is, $c_{\tau_{i}}>p-w$ ). Similar assumptions can be found in the literature; see, for example, Taylor and Plambeck (2007). When there are multiple equilibria in capacity reservation levels, which occur when both firms choose first-priority capacity and the capacity reservation price is high, or when the capacity reservation price exactly equals the threshold value of each region (defined in the proposition below). In the former case, the symmetric equilibrium is selected that results in a fair split of profits between the buying firms. In the latter case, all equilibria are payoff-invariant and we therefore assume that the one in the proposition below is selected without loss of generality. The following result shows the equilibrium capacity reservation levels for given capacity reservation types by both firms.

Proposition 1. (Equilibrium CAPacity Reservation LeveL). Consider $c_{\tau_{i}} \leq(p-w) \alpha$. There are three scenarios contingent on the capacity reservation types $\left(\tau_{1}, \tau_{2}\right)$ :

(i) Both firms reserve exclusive capacity, that is, $\left(\tau_{1}, \tau_{2}\right)=(e, e)$. The equilibrium capacity reservation level is $k_{i}^{e e}=H$. 
(ii) One firm, say firm 1, reserves exclusive capacity while the other firm reserves first-priority capacity, that is, $\left(\tau_{1}, \tau_{2}\right)=(e, f)$. The other case is symmetric. The equilibrium capacity reservation level $k_{i}^{e f}$ is as follows:

Firm 1 with type e : $k_{1}^{e f}= \begin{cases}H & \text { if } c_{e} \leq(p-w) \alpha \beta \\ L & \text { if } c_{e}>(p-w) \alpha \beta\end{cases}$

Firm 2 with type $f: k_{2}^{e f}=H$.

(iii) Both firms reserve first-priority capacity, that is, $\left(\tau_{1}, \tau_{2}\right)=(f, f)$. The equilibrium capacity reservation level $k_{i}^{f f}$ is as follows:

$$
k_{i}^{f f}= \begin{cases}H & \text { if } c_{f} \leq(p-w) \alpha \beta \\ \frac{H+L}{2} & \text { if } c_{f}>(p-w) \alpha \beta\end{cases}
$$

We make the following observations from the proposition. When both firms choose exclusive reservations, the only capacity level that is supported in equilibrium is $(H, H)$. This occurs because a firm cannot access the other's leftover capacity and the marginal cost of capacity reservation is less than the expected profit from any additional unit of capacity beyond $L: c_{e} \leq(p-w) \alpha$. For all other equilibria, the capacity reservation level depends on the price of the capacity reservation $\left(c_{e}\right.$ and $\left.c_{f}\right)$ and demand correlation $(\beta)$. Under both the $(e, f)$ and $(f$, f) regimes, the equilibrium capacity level is (weakly) increasing in demand correlation. This occurs because, as the correlation increases, it becomes less likely that the firm is able to access the other firm's capacity when needed, and each firm thus needs to raise the capacity reservation level to cover its own demand.

Another interesting finding to note is that an equilibrium exists under which firm 1 induces firm 2 to reserve more first-priority capacity ( $H$ units) when firm 1 itself reserves less exclusive capacity ( $L$ units). This equilibrium is likely to occur when exclusive capacity is expensive (thus, it is too costly to reserve $H)$ and the demand correlation $(\beta)$ is low.

Finally, we observe that, under the $(f, f)$ equilibrium, both firms reserve $H$ when correlation is high and $\frac{H+L}{2}$ when correlation is low. To see this, consider the case where correlation is close to 1 . Then the chance of using the other's capacity is low, with the result that each firm builds sufficient capacity to cover its own demand. The opposite happens when the correlation is low or negative. When the firm sees high demand, the chance that the other firm has leftover capacity is high, thus reducing the capacity reservation level needed to fulfill the demand.

\subsection{Capacity Reservation Type Choices}

We next characterize in the following proposition how firms choose the capacity type in equilibrium given the capacity reservation prices $\left(c_{e}, c_{f}\right)$. For ease of exposition, we show the result by varying $c_{e}$ for a given $c_{f}$.

Proposition 2. (EQUILIBRIUM CAPACITY TYPE CHorces). Given $c_{f}$ and $\beta$, the following result characterizes the equilibrium capacity type.

(i) If $c_{e}=c_{f} \leq(p-w) \alpha \beta$, both firms are indifferent between choosing $e$ and $f$. If $c_{e}=c_{f}>(p-w) \alpha \beta$, choosing $e$ is a weakly dominant strategy for both firms.

(ii) If $c_{e} \geq c_{f}$, there exists a threshold $\bar{c}_{e}\left(c_{f} ; \beta\right)$ such that the equilibrium capacity type is $(e, f)($ or $(f, e))$ for $c_{e} \leq \bar{c}_{e}\left(c_{f} ; \beta\right)$ and $(f, f)$ for $c_{e} \geq \bar{c}_{e}\left(c_{f} ; \beta\right)$.

If $c_{e}=c_{f} \leq(p-w) \alpha \beta$, the reservation price is low and both firms reserve $H$ units of capacity regardless of the type. Therefore, both firms can always satisfy demand with their own capacity and are indifferent between the two capacity types. We next explain why choosing $e$ is the weakly dominant strategy when $c_{e}=c_{f}>(p-w) \alpha \beta$. When firm $j$ chooses exclusive capacity, firm $i$ is indifferent between choosing exclusive or first-priority capacity, because both types of capacity cost are the same (since $c_{e}=c_{f}$ ). When firm $j$ chooses first-priority capacity, firm $i$ is better off reserving capacity exclusively, as doing so forces firm $j$ to reserve more. As a result, it is a dominant strategy for both firms to reserve capacity exclusively. We later show, however, that the weak dominance of exclusive capacity (hence, the $(e, e)$ equilibrium) can make both firms worse off in Proposition 3.

Now consider the case of $c_{e} \geq c_{f}$, which occurs when the supplier gives a discount if the buying firm allows the supplier to use leftover capacity, or charges a premium if the buying firm demands exclusivity. In this case, the difference in reservation prices is critical. When $c_{e}$ is slightly greater than $c_{f}$, that is, $c_{f} \leq c_{e} \leq \bar{c}_{e}\left(c_{f} ; \beta\right)$, interestingly, one firm is willing to choose the more expensive exclusive capacity in equilibrium, that is, $(e, f)$ emerges as an equilibrium. To see why, if firm $j$ chooses first-priority capacity, firm $i$ should choose exclusive capacity, because doing so forces firm $j$ to build a larger capacity that firm $i$ can tap into (as in discussions following Proposition 1). In particular, when demand correlation is low or negative, the good chance of tapping into the other firm's capacity reduces firm $i$ 's capacity reservation level. If firm $j$ chooses exclusive capacity, firm $i$ should choose first-priority capacity because it is cheaper and firm $i$ cannot access firm $j$ 's leftovers in any case. Therefore, in this situation, the firms settle in an equilibrium where one firm free-rides on the other firm's unused capacity. However, when $c_{e}$ is sufficiently high, 
$c_{e} \geq \bar{c}_{e}\left(c_{f} ; \beta\right)$, first-priority capacity is considerably cheaper and both firms choose $f$.

We then investigate an important question: when is the resulting equilibrium efficient for both firms? The following results show that the equilibrium outcome can be inefficient for the buying firms in two ways.

Proposition 3. (Adverse Equilibria for the BuYING FIRMS). Given $c_{f}$ and $\beta$,

(i) When $c_{e}=c_{f}>(p-w) \alpha \beta$, a prisoner's dilemma equilibrium occurs, where both firms could have increased their profits if both of them had chosen first-priority capacity instead of exclusive capacity.

(ii) When $c_{f} \leq c_{e} \leq \bar{c}_{e}\left(c_{f} ; \beta\right)$, a free-rider equilibrium occurs, where the one firm chooses first-priority capacity while the other firm chooses exclusive capacity.

When $c_{e}$ is considerably larger than $c_{f}$ $\left(c_{e}>\bar{c}_{e}\left(c_{f} ; \beta\right)\right)$, the capacity reservation price becomes the dominant driver, and both firms choosing the less expensive option (first-priority) is efficient.

When $c_{e}$ falls between $c_{f}$ and $\bar{c}_{e}\left(c_{f} ; \beta\right)$, the equilibrium outcomes become inefficient. For instance, if $c_{e}=c_{f}>(p-w) \alpha \beta$ (when there is no price gap between exclusive and first-priority reservations), both firms' choosing exclusive capacity is an equilibrium, but both firms could have improved their profits had they chosen first-priority capacity together. The reason for this result is that both firms are able to access the other's leftover capacity and leverage capacity pooling under first-priority capacity. Therefore, both firms can build smaller capacity, that is, $k_{i}^{f f}<k_{i}^{e e}$ (see Proposition 1), and earn a higher profit with first-priority capacity.

When first-priority capacity becomes slightly cheaper, that is, $c_{f} \leq c_{e} \leq \bar{c}_{e}\left(c_{f} ; \beta\right)$, a free-rider equilibrium arises because one firm chooses exclusive capacity while the other firm is willing to choose firstpriority capacity (part (ii) of Proposition 2). In this case, the firm reserving exclusive capacity would have been better off if it had reserved the sameamount as first-priority (since $c_{f}<c_{e}$ ). However, doing so could not induce the other firm to reserve $H$ units of first-priority capacity. Hence, the firm had to burn money to induce the other firm to reserve more. Figure 2 illustrates Propositions 2 and 3.

While Propositions 2 and 3 describe how the equilibrium outcomes are affected by capacity reservation prices and their difference, the following results describe how demand correlation changes the equilibrium outcome.

Proposition 4. (Impact of Demand Correlation). The threshold $\bar{c}_{e}\left(c_{f} ; \beta\right)$ decreases in $\beta$. Hence, the free-rider region shrinks as demand correlation $(\rho)$ increases.
Figure 2 Equilibrium Capacity Type Choices (given first-priority capacity cost $c_{f}$ and demand correlation $\rho$ )

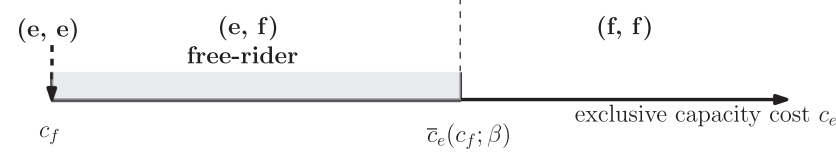

Note. The prisoner's dilemma occurs when $c_{e}=c_{f}>(p-w) \alpha \beta$.

We illustrate the proposition in Figure 3. Note that the free-rider region, $(e, f)$, occurs when firm $i$ chooses the more expensive exclusive capacity to induce firm $j$ (who chooses the cheaper first-priority capacity) to reserve more capacity. When the demand correlation increases, firm $i^{\prime}$ s chance to access firm $j$ 's leftovers decreases. Hence, the savings from free-riding decrease. When the correlation becomes sufficiently large, firm $i$ will be better off reserving the less expensive first-priority capacity, and thus the equilibrium outcome switches from $(e, f)$ to $(f, f)$.

To study the impact of correlation in isolation, let us consider the case where reservation costs are the same for both types that is, $c_{e}=c_{f}$. We note that the firm supplies products such as fertilizers and pesticide in the agricultural supply industry where demands are highly correlated and impacted by seasonality. Therefore, the buying firm's demand has a very high correlation with other firms in the same industry. Figure 3 illustrates that, when the demand correlation is quite high, the chance for one firm to use the other's leftover is quite small. In this case, neither the supplier (since it is able to set the same price for both types of capacity) nor the buyers (due to the high demand correlation) care about the capacity type. In other words, whether the firm chooses exclusive or first-priority capacity has the same impact (thus the first-priority capacity is de facto exclusive). On the other hand, when demand correlation is not high as in the cosmetics example, then the exclusive capacity can be chosen.

Figure 3 Impact of Demand Correlation on Equilibrium Capacity Types (given first-priority capacity cost $c_{f}$ )

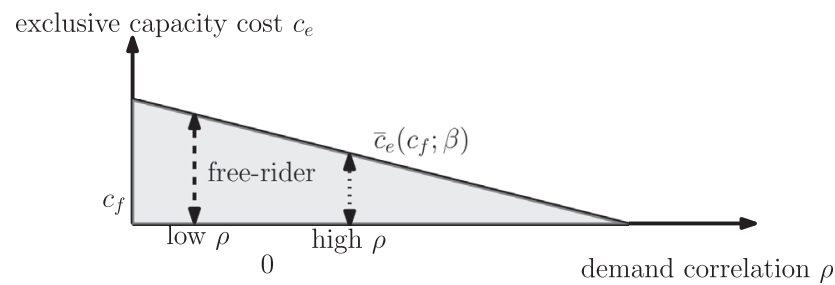

Note. For example, as the demand correlation increases from the low $\rho$ to the high $\rho$ value, the free-rider region (indicated by the dashed and dotted lines, respectively) shrinks. 


\section{Supplier's Capacity Reservation Prices}

In section 3, we analyzed how buying firms should reserve capacity for given reservation prices $c_{e}$ and $c_{f}$. In this section, we consider the supplier's problem to strategically choose the reservation price of each capacity type. With the endogenous pricing decision of the strategic supplier, we now have a two-stage game where the supplier chooses capacity prices $c_{e}$ and $c_{f}$ in the first stage, and the two buying firms will play the second-stage game that has been modeled and analyzed in section 3 . We focus on a setting where the supplier only installs the capacity reserved by the two buyers. We discuss the implications of this assumption in section 4.1.

Specifically, consider the profit for the supplier who chooses capacity prices $c_{e}$ and $c_{f}$. Then, firms 1 and 2 will choose capacity types $\tau_{1}$ and $\tau_{2}$ and capacity level $k_{1}^{\tau_{1} \tau_{2}}$ and $k_{2}^{\tau_{1} \tau_{2}}$ according to the subgame perfect equilibrium in Propositions 1 and 2. Then, the expected profit of the supplier is:

$$
\begin{aligned}
\pi_{s}^{\tau_{1} \tau_{2}}\left(c_{e}, c_{f}\right)= & \sum_{i, j=1, i \neq j}^{2}\left\{w E \left[\operatorname { m i n } \left\{D_{i}, k_{i}^{\tau_{1} \tau_{2}}\right.\right.\right. \\
& \left.\left.\left.+\left(k_{j}^{\tau_{1} \tau_{2}}-D_{j}\right)^{+} \mathbb{1}_{\left\{\tau_{j}=f\right\}}\right\}\right]+\left(c_{\tau_{i}}-\gamma\right) k_{i}^{\tau_{1} \tau_{2}}\right\},
\end{aligned}
$$

where $\gamma$ represents the additional capacity installation cost (or investment) that the supplier needs to incur to secure reserved capacity.

We obtain the supplier's equilibrium capacity reservations prices in the following proposition.

Proposition 5. (Equilibrium Capacity Reservation PrICES). In equilibrium, the supplier chooses $c_{e}^{*}=(p-w) \alpha$ and $c_{f}^{*}=c_{e}^{*}$. Consequently, both firms are trapped in the prisoner's dilemma when both firms choose exclusive capacity in equilibrium.

We note that the supplier's profit has two parts: the production profit (from the wholesale prices of fulfilled orders) and the reservation profit (from the capacity reservation fee). The production profit is determined by overall capacity and the flexibility in utilizing the leftover capacity (which will determine how the capacity is used), while the capacity reservation profit is determined by the capacity types (and therefore the corresponding reservation prices) and levels. We next discuss the trade-off the supplier faces when deciding capacity prices.

If the supplier decides to induce both firms to choose first-priority capacity, it must offer a discount so that first-priority capacity is appealing to the buyers. However, since each firm can access the other's leftovers, buyers can leverage demand pooling, which can lead to a decrease in total capacity. As a result, the supplier earns less capacity reservation profit. In this case, the supplier is flexible in utilizing the leftover capacity to satisfy both firms' orders, and the benefit from this arrangement is evident when one firm sees demand $H$ while the other sees $L$. However, despite the flexibility in utilizing the reserved capacity to serve the demand, the supplier does not necessarily earn a higher production profit because the total reserved capacity may be smaller.

On the other hand, if the supplier decides to induce both firms to choose exclusive capacity, the supplier sets the capacity reservation prices to be the same under both exclusive and first-priority capacity, and the buying firms reserve a larger capacity since they cannot access each other's leftovers. Thus, the supplier earns a larger capacity reservation profit under exclusive capacity and the production profit can also be higher if the total reservation level is sufficiently large. This situation can be achieved by setting $c_{e}^{*}=c_{f}^{*}=(p-w) \alpha$. The supplier's profit under the scenario where one firm chooses exclusive capacity and the other chooses first-priority capacity is between the two extreme cases.

We observe that by setting the capacity reservation prices of $c_{e}^{*}=c_{f}^{*}=(p-w) \alpha$, the supplier is able to induce both firms to reserve exclusive capacity: in fact, one can see that $c_{e}=(p-w) \alpha$ is the highest price that can still induce buyers to reserve $H$ units of exclusive capacity. Thus, the supplier is able to extract more reservation profit (from the larger reserved capacity) without compromising any production profit. As such, it is optimal for the supplier to set the capacity reservation prices this way. As a side note, although there exist two possible equilibria when $c_{e}^{*}=c_{f}^{*}$, in order to ensure both firms to choose exclusive capacity, the supplier may add an arbitrarily small premium of $\varepsilon>0$ to the capacity reservation price of first-priority capacity and make first-priority capacity slightly more expensive than exclusive capacity.

REMARK. We consider that the strategic supplier determines capacity reservation prices $c_{e}$ and $c_{f}$ instead of wholesale prices for two reasons. First, we would like to isolate the impact of capacity reservation prices from other strategic considerations. If the wholesale price is endogenized, for example, there can be scenarios in which a higher capacity reservation price is compensated for by a lower wholesale price, diluting the focus of the analysis. Second, this setting also follows the 
convention of the capacity reservation literature, cf., $\mathrm{Li}$ et al. (2011), whereby the wholesale price $w$ is exogenously given while the capacity reservation prices are endogenized.

\subsection{Supplier's Capacity Installation Decisions}

In the base model, we implicitly assume that the supplier only installs the capacity reserved by the buyers. In this section, we explore the possibility that the supplier may install an additional $k_{s}$ units of capacity besides those $k_{1}+k_{2}$ reserved by the buying firms. To access the additional $k_{s}$ units of capacity, the firms do not need to pay the capacity reservation price. To allocate the $k_{s}$ units of capacity between the two buying firms without inducing order quantity manipulation, we adopt the uniform allocation rule (Cachon and Lariviere 1999). As a result, firm $i$ is able to access $k_{s} / 2$ units of the "free" capacity plus any leftover from firm $j$ 's allocated free capacity. We assume the buying firms first use their reserved (either exclusive or first-priority) capacity before using the unattached free capacity to satisfy their demand.

To analyze the supplier's additional capacity installation decision, we define the residual demand $D_{r}^{\tau_{1} \tau_{2}}\left(k_{1}, k_{2}\right)$, which is the total demand not satisfied by the reserved capacities $k_{1}$ and $k_{2}$, as follows.

$$
D_{r}^{\tau_{1} \tau_{2}}\left(k_{1}, k_{2}\right)=\sum_{i, j=1, i \neq j}^{2}\left[D_{i}-k_{i}-\left(k_{j}-D_{j}\right)^{+} \mathbb{1}_{\left\{\tau_{j}=f\right\}}\right]^{+}
$$

It is immediate that the residual demand decreases in the reserved capacities $k_{1}$ and $k_{2}$ in the usual stochastic order sense ${ }^{3}$ as characterized in the following lemma.

LEMMA 2. For any $k_{1}, k_{2}, \hat{k}_{1}$, and $\hat{k}_{2}$ such that $0 \leq k_{1} \leq \hat{k}_{1}$ and $0 \leq k_{2} \leq \hat{k}_{2}$, the residual demand $D_{r}^{\tau_{1} \tau_{2}}\left(k_{1}, k_{2}\right) \geq_{s t} D_{r}^{\tau_{1} \tau_{2}}\left(\hat{k}_{1}, \hat{k}_{2}\right)$.

Intuitively, the more capacity reserved by the buying firms, the less residual demand there might be. To satisfy the residual demand, the supplier may install additional $k_{\mathrm{s}}$ units of capacity. The supplier's decision problem is as follows:

$$
\max _{k_{s}} w E\left[\min \left\{D_{r}^{\tau_{1} \tau_{2}}\left(k_{1}, k_{2}\right), k_{s}\right\}\right]-\gamma k_{s},
$$

Solving the supplier's decision problem, we obtain the following results. Let $k_{s}^{*}\left(k_{1}, k_{2} ; \tau_{1}, \tau_{2}\right)$ denote the supplier's optimal free capacity decision.

Proposition 6. Given the capacity reservation types $\left(\tau_{1}, \tau_{2}\right)$, the supplier's optimal free capacity $k_{s}^{*}\left(k_{1}, k_{2} ; \tau_{1}, \tau_{2}\right)$ decreases in $k_{1}$ and $k_{2}$. In addition, if $w<\gamma$, the supplier's optimal free capacity is as follows:

$$
k_{s}^{*}\left(k_{1}, k_{2} ; \tau_{1}, \tau_{2}\right)=0 .
$$

The first observation from the proposition is that the optimal free capacity decreases in the reserved capacities by the buying firms. Intuitively, the reserved capacity and the free capacity are substitutes to satisfy the demand. Thus, the more capacity both firms reserve, the less free capacity the supplier should install. The second observation is that the optimal free capacity depends on the relationship between the wholesale price $w$ (as well as the probability distribution of the residual demand) and the capacity installation cost $\gamma$. When the wholesale price is lower than the capacity installation cost, the supplier has no incentive to install additional capacity. This case echoes the base model setting. In such a scenario, unless the buying firm pays a fee to reserve the capacity, the supplier will not build any free capacity. Thus, the total installed capacity equals to the reserved capacity by the buying firms.

We next make the following observation on the consequence if the condition $w<\gamma$ is grossly violated. Recall that neither buying firm has incentives to reserve a capacity higher than $H$; that is, $k_{i} \leq H, i=1,2$.

OBSERVATION 1. If $w \alpha \beta>\gamma$, the supplier's optimal free capacity is:

$$
k_{s}^{*}\left(k_{1}, k_{2} ; \tau_{1}, \tau_{2}\right)=2 H-k_{1}-k_{2} .
$$

When the wholesale price is sufficiently high, the supplier will install a sufficient amount of free capacity to cover all the residual demand. In this case, given the free capacity level $k_{s}^{*}\left(k_{1}, k_{2} ; \tau_{1}, \tau_{2}\right)$, firm 1 's expected profit function under capacity type $\left(\tau_{1}, \tau_{2}\right)$ is as follows; firm 2's profit function can be obtained similarly and is therefore omitted for brevity.

$$
\begin{aligned}
\pi_{1}^{\tau_{1} e}\left(k_{1}, k_{2} ; k_{s}\right)= & (p-w) E\left[\operatorname { m i n } \left\{D_{1}, k_{1}+\frac{2 H-k_{1}-k_{2}}{2}\right.\right. \\
& \left.\left.+\left(\frac{2 H-k_{1}-k_{2}}{2}-\left(D_{2}-k_{2}\right)^{+}\right)^{+}\right\}\right]-c_{\tau_{1}} k_{1} \\
\pi_{1}^{\tau_{1} f}\left(k_{1}, k_{2} ; k_{s}\right)= & (p-w) E\left[\operatorname { m i n } \left\{D_{1}, k_{1}+\frac{2 H-k_{1}-k_{2}}{2}\right.\right. \\
& \left.\left.+\left(k_{2}+\frac{2 H-k_{1}-k_{2}}{2}-D_{2}\right)^{+}\right\}\right]-c_{\tau_{1}} k_{1} .
\end{aligned}
$$

In either case, the minimum capacity for firm 1 is obtained when $D_{2}=H$ as follows: 


$$
\begin{aligned}
& k_{1}+\frac{2 H-k_{1}-k_{2}}{2}+\left(\frac{2 H-k_{1}-k_{2}}{2}-H+k_{2}\right)^{+} \\
& =H-\frac{k_{2}-k_{1}}{2}+\left(\frac{k_{2}-k_{1}}{2}\right)^{+} \geq H
\end{aligned}
$$

Thus, firm 1's demand is always satisfied regardless of the capacity reservation level $k_{1}$, and it is optimal for firm 1 to reserve $k_{1}=0$. Intuitively, anticipating that the supplier will install sufficient capacity to cover the residual demand, neither buying firm has incentives to pay a fee to reserve the capacity in the earlier stage. Thus, the capacity reservation by the buying firms is not a key concern in such a setting.

To summarize, one sufficient condition to guarantee that the supplier commits not to install additional free capacity besides those reserved by the buying firms is $w<\gamma$. If the condition is grossly violated, for example, when the wholesale price is sufficiently high (see Observation 1 above), the supplier may have incentives to install ample capacity to satisfy the demand. In such a scenario, the capacity reservation by the buying firm is not a key issue.

\section{Capacity Reservation with Transfer Price}

In the previous section, we have shown that when the supplier strategically determines reservation prices, the supplier does so in a way that both firms reserve a large quantity of exclusive capacity. If the supplier further increases reservation prices, buyers will reserve less capacity and will reduce the supplier's profit. In fact, we show that the supplier charges the highest price that induces reserving $H$ units of exclusive capacity. From the buying firm's perspective, both firms are induced to reserve $H$ units of capacity to cover its demand in all scenarios. While it seems intuitive to declare this to be the best scenario for the supplier, we now show that there is a capacity sharing arrangement under which the supplier can charge a higher price for capacity while both buyers also increase their profits by avoiding over-reservation.

In this section, we propose the use of capacity reservation with transfer price between two buying firms in order to improve supply chain efficiency. The underlying idea is that a buying firm charges the other firm a fee when it uses the leftover capacity. Specifically, if firm $i$ reserves the capacity and the leftovers get used by firm $j$, then firm $j$ directly pays firm $i$ at a price of $t_{i}$ per unit of the used capacity. This transfer price payment is essentially a form of tradable capacity option, which is used in practice. For instance, TSMC pioneered selling tradable capacity options (Economist 1996, LaPedus 1995, Plambeck and Taylor 2007). The capacity transfer price also runs along the same lines as the transfer payment contract in Roels and Tang (2017).

In what follows, we consider the capacity reservation with transfer price (named as "transferrable capacity" for brevity). ${ }^{4}$ We use $t$ to refer to this capacity type, $c_{t}$ to denote the price of reserving one unit of transferable capacity, and $t_{i}$ to denote the capacity transfer prices from firm $j$ to firm $i$ (if firm $i$ chooses transferrable capacity.) Then we have firm $i$ 's expected profit for given capacity-type choices $\left(\tau_{1}, \tau_{2}\right)$ where $\tau_{i} \in\{e, t\}$ as follows.

$$
\begin{aligned}
& \pi_{i}^{\tau_{1} \tau_{2}}\left(k_{1}, k_{2}\right)=(p-w) E\left[\min \left\{D_{i}, k_{i}\right\}\right] \\
& +t_{i} E\left[\min \left\{\left(D_{j}-k_{j}\right)^{+},\left(k_{i}-D_{i}\right)^{+}\right\}\right] \mathbb{1}_{\left\{\tau_{i}=t\right\}} \\
& +\left(p-w-t_{j}\right) E\left[\min \left\{\left(D_{i}-k_{i}\right)^{+},\left(k_{j}-D_{j}\right)^{+}\right\}\right] \\
& \mathbb{1}_{\left\{\tau_{j}=t\right\}}-c_{\tau_{i}} k_{i} \\
& =(p-w) E \\
& {\left[\min \left\{\begin{array}{c}
D_{i}+\frac{t_{i}}{p-w} \min \left\{\left(D_{j}-k_{j}\right)^{+},\left(k_{i}-D_{i}\right)^{+}\right\} \mathbb{1}_{\left\{\tau_{i}=t\right\}}, \\
k_{i}+\left(1-\frac{t_{j}}{p-w}\right) \min \left\{\left(D_{i}-k_{i}\right)^{+},\left(k_{j}-D_{j}\right)^{+}\right\} \mathbb{1}_{\left\{\tau_{j}=t\right\}}
\end{array}\right\}\right]} \\
& -c_{\tau_{i}} k_{i}
\end{aligned}
$$

We note that the transfer price $t_{i}$ should not be greater than the unit profit margin, that is, $t_{i} \leq p-w$. Otherwise, firms will simply not transfer any capacity and the firms' decisions degenerate to exclusive capacity. We therefore simplify the transfer price decision by defining $\hat{t}_{i} \triangleq \frac{t_{i}}{p-w}$. Hence, deciding a transfer price $t_{i}$ is equivalent to deciding $\hat{t}_{i} \in[0,1]$. Therefore, the expected profit for firm $i$ for a given pair of transfer prices $\left(\hat{t}_{1}, \hat{t}_{2}\right)$ is as follows.

$$
\begin{aligned}
& \pi_{i}^{\tau_{1} \tau_{2}}\left(k_{1}, k_{2}\right)=(p-w) E \\
& {\left[\min \left\{\begin{array}{c}
D_{i}+\hat{t}_{i} \min \left\{\left(D_{j}-k_{j}\right)^{+},\left(k_{i}-D_{i}\right)^{+}\right\} 1_{\left\{\tau_{i}=t\right\}}, \\
k_{i}+\left(1-\hat{t}_{j}\right) \min \left\{\left(D_{i}-k_{i}\right)^{+},\left(k_{j}-D_{j}\right)^{+}\right\} 1_{\left\{\tau_{j}=t\right\}}
\end{array}\right\}\right]} \\
& -c_{\tau_{i}} k_{i}
\end{aligned}
$$

Comparing Equations (8) to (1), we observe that the impact of the transfer price is twofold. On the demand side, we observe that the effective demand increases from $D_{i}$ to $D_{i}+\hat{t}_{i} \min \left\{\left(D_{j}-k_{j}\right)^{+}\right.$, $\left.\left(k_{i}-D_{i}\right)^{+}\right\}$under transferrable capacity. Intuitively, for a unit of firm $j^{\prime}$ s demand satisfied by firm $i^{\prime} s$ reserved capacity, firm $i$ is able to accrue a unit profit of $t_{i}$, which is equivalent to firm $i$ 's own demand increases by $\hat{t}_{i}$ unit. On the capacity side, compared to the first-priority capacity case, the effective capacity to firm $i$ shrinks from $k_{i}+\left(k_{j}-D_{j}\right)^{+}$to $k_{i}+\left(1-\hat{t}_{j}\right) \min \left\{\left(D_{i}-k_{i}\right)^{+},\left(k_{j}-D_{j}\right)^{+}\right\}$. This occurs because, if firm $i$ accesses the reserved capacity by 
firm $j$, it will incur an additional cost of $t_{j}$ compared to the first-priority capacity case. This additional cost is reflected by the shrinking effective capacity observed above. Compared to the exclusive capacity case, however, the available capacity to firm $i$ increases from $k_{i}$ to $k_{i}+\left(1-\hat{t}_{j}\right) \min \left\{\left(D_{i}-k_{i}\right)^{+},\left(k_{j}-D_{j}\right)^{+}\right\}$. This observation is intuitive as firm $i$ is able to access firm $j$ 's leftover capacity, albeit at a higher cost.

When both firms choose transferrable capacity, we focus on the symmetric scenario where the capacity transfer prices are the same, that is, $\hat{t}_{1}=\hat{t}_{2}=\hat{t}$, as the two firms are ex ante symmetric otherwise. Similar to our previous analysis, we consider the case where $c_{e} \leq(p-w) \alpha$ and $c_{t} \leq(p-w) \alpha[1+\hat{t}(1-\beta)]$. Otherwise, it is trivial to show that the firms will not reserve any capacity beyond the lower bound $L$ when both firms choose exclusive capacity or transferrable capacity.

As in section 3, we first study the equilibrium reservation level for a given capacity transfer price $\hat{t}$. When there exist multiple equilibria with different reservation levels, we choose the one that yields the largest production (the highest utilization of the reserved capacity). If all equilibria yield the same utilization of the reserved capacity, then we select the outcome with the fairest split of profits between the buying firms. If all equilibria are payoff-invariant (at the boundary of the regions defined in the proposition below), we assume the one in the proposition below is selected without loss of generality.

Proposition 7. (Equilibrium Capacity Reservation LeVEL). Consider $c_{e} \leq(p-w) \alpha$ and $c_{t} \leq(p-w)$ $\alpha[1+\hat{t}(1-\beta)]$. There are three scenarios contingent on the capacity reservation types $\left(\tau_{1}, \tau_{2}\right)$ for a given capacity transfer price $\hat{t}$ :

(i) Both firms reserve exclusive capacity, that is, $\left(\tau_{1}, \tau_{2}\right)=(e, e)$. The equilibrium capacity reservation level is $k_{i}^{e e}=H$.

(ii) Firm 1 reserves exclusive capacity while firm 2 reserves transferrable capacity, that is, $\left(\tau_{1}, \tau_{2}\right)=(e, t)$. The other case is symmetric. The equilibrium capacity reservation level $\left(k_{1}^{e t}, k_{2}^{e t}\right)$ is as shown in Figure 4.

(iii) Both firms reserve transferrable capacity, that is, $\left(\tau_{1}, \tau_{2}\right)=(t, t)$. The equilibrium capacity reservation level $k_{i}^{\text {tt }}$ is as follows:

$$
k_{i}^{t t}= \begin{cases}H & \text { if } c_{t} \leq(p-w) \alpha[\beta+\hat{t}(1-\beta)] \\ \frac{H+L}{2} & \text { if } c_{t}>(p-w) \alpha[\beta+\hat{t}(1-\beta)] .\end{cases}
$$

Proposition 7 mirrors Proposition 1 in several ways. First, as in Proposition 1(i), when both firms reserve exclusive capacity, the only capacity level supported is $H$ for exactly the same reason.
Parts (ii) and (iii) describe the cases where at least one firm chooses transferable capacity. Part (ii) of Proposition 7 is analogous to the equilibrium reservation level in the $(e, f)$ case (Proposition 1(ii)). As before, the equilibrium capacity level depends on the reservation prices and demand correlation, both of which define the switching curves in Figure 4. Note that the switching curve monotonically changes in demand correlation.

Comparing Propositions 1(iii) and 7(iii), we observe that the capacity reservation level in the $(t, t)$ case is higher than that in the $(f, f)$ case for the same reservation price, $c_{t}=c_{f}$. To see why, first note that the firm does not gain any profit from lending its leftovers to the other firm under first-priority capacity. However, in the $(t, t)$ case, the same action brings in additional profit, as the other firm pays to access the leftover capacity, which reduces the obsolescence cost of the reserved capacity. Hence, the firms reserve more under $(t, t)$. We note that if $\hat{t}=0$, the capacity reservation level degenerates to that under first-priority capacity. As in Proposition 1, the capacity level depends on demand correlation. As the correlation increases, the firm is less likely to access the other firm's leftover capacity, and thus needs to reserve more capacity.

We next analyze the buyers' equilibrium capacity type choices in the following proposition.

Proposition 8. (Equilibrium CApacity Type Choices). For a given capacity transfer price $\hat{t}$, transferrable capacity reservation price $c_{t}$, and proxy demand correlation $\beta$, there exist two thresholds $\tilde{c}_{e}\left(c_{t} ; \beta, \hat{t}\right)$ and $\hat{c}_{e}\left(c_{t} ; \beta, \hat{t}\right)$ such that, in equilibrium,

(i) when $c_{e} \leq \tilde{c}_{e}\left(c_{t} ; \beta, \hat{t}\right)$, both firms reserve exclusive capacity;

(ii) when $\tilde{c}_{e}\left(c_{t} ; \beta, \hat{t}\right)<c_{e} \leq \hat{c}_{e}\left(c_{t} ; \beta, \hat{t}\right)$, one firm reserves exclusive capacity and the other firm reserves transferrable capacity;

Figure 4 Equilibrium Capacity Reservation Level $\left(\boldsymbol{k}_{1}^{e t}, \boldsymbol{k}_{2}^{e t}\right)$

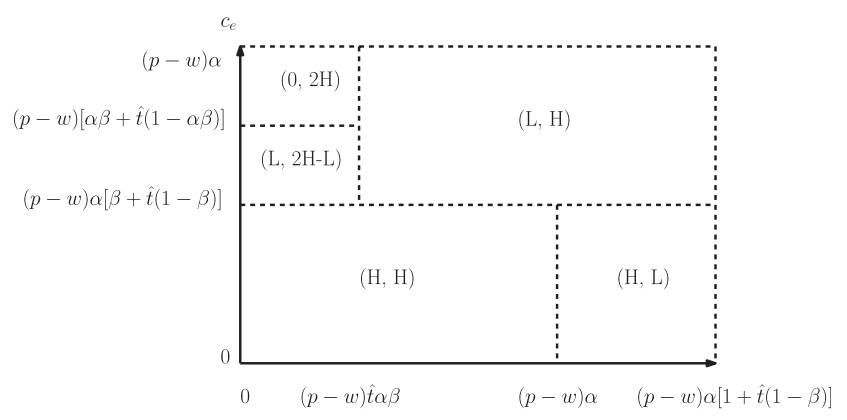

$c_{t}$

Note. The figure shows the case when $\hat{t} \leq \frac{\alpha(1-\beta)}{1-\alpha \beta}$. When $\hat{t}>\frac{\alpha(1-\beta)}{1-\alpha \beta}$, the outcome is similar with the upper left region $(0,2 H)$ replaced by $(L$, $2 H-L)$. 
(iii) when $\hat{c}_{e}\left(c_{t} ; \beta, \hat{t}\right)<c_{e}$, both firms reserve transferrable capacity.

When exclusive capacity is much cheaper than transferrable capacity (case i), it is expected that both firms reserve exclusive capacity. On the other hand, when transferrable capacity is much cheaper (case iii), it is also expected that both firms reserve transferrable capacity. In the middle range $\left(\tilde{c}_{e}\left(c_{t} ; \beta, \hat{t}\right)<c_{e} \leq\right.$ $\left.\hat{c}_{e}\left(c_{t} ; \beta, \hat{t}\right)\right)$, however, one firm chooses transferrable capacity even if it might be slightly more expensive because it may earn a positive profit from the reserved capacity utilized by the other firm, while the other chooses exclusive capacity, incentivizes the former firm to build a larger amount of transferrable capacity, and utilizes the leftover capacity if any.

We next characterize the supplier's equilibrium capacity reservation prices, building on the subgame perfect equilibrium capacity-type choices and reservation levels.

Proposition 9. (Equilibrium Capacity Reservation PRICES). There exists a threshold $\underline{t}$ such that

(i) if $\hat{t} \leq \underline{t}$, the supplier sets capacity reservation prices $\left(c_{e}^{*}, c_{t}^{*}\right) \quad$ such that $c_{e}^{*}=(p-w) \alpha$ and $c_{e}^{*} \leq \tilde{c}_{e}\left(c_{t}^{*} ; \beta, \hat{t}\right)$. Both firms choose exclusive capacity in equilibrium.

(ii) if $\hat{t}>\underline{t}$, the supplier sets capacity reservation prices $\left(c_{e}^{*}, c_{t}^{*}\right)$ such that $c_{t}^{*}=(p-w) \alpha[1+\hat{t}(1-\beta)]$ and $c_{e}^{*} \geq \hat{c}_{e}\left(c_{t}^{*} ; \beta, \hat{t}\right)$. Both firms choose transferrable capacity in equilibrium.

Note that the optimal capacity price and equilibrium region depend on the unit-price of traded capacity $(\hat{t})$ and demand correlation, which defines the two thresholds $-\tilde{c}_{e}\left(c_{t}^{*} ; \beta, \hat{t}\right)$ and $\hat{c}_{e}\left(c_{t}^{*} ; \beta, \hat{t}\right)$. We note that when the capacity transfer price $\hat{t}$ is large enough, the supplier may prefer to set the capacity reservation prices such that both firms choose transferrable capacity in equilibrium. This capacity reservation price decision is in sharp contrast with the results in Proposition 5, where the supplier always induces buying firms to choose exclusive capacity. To understand why the supplier prefers to induce transferrable capacity, we note that although the total reserved capacity $(\mathrm{H}+\mathrm{L})$ is lower than the one where both firms choose exclusive capacity $(2 \mathrm{H})$, the supplier is able to charge a much higher capacity reservation price $(p-w) \alpha[1+\hat{t}(1-\beta)]$. This observation follows that the firms have a higher valuation about transferrable capacity because of the opportunity to earn profit from the capacity transfer price on any idle capacity. Therefore, the supplier's profit is higher when both firms choose transferrable capacity.

We have shown that the supplier may benefit from transferrable capacity. We show in the next proposition that the buyers can also benefit from trading the reserved capacity with each other. This proposition sheds lights on a range of transfer prices that should be used to induce a win-win-win outcome: the outcome that is desired by all parties.

Proposition 10. (PARETO-IMProvement Region of Capacity Transfer Price $\hat{t}$ ). When the proxy demand correlation $\beta \leq \frac{\gamma}{p \alpha}$, there exist two thresholds $\underline{t}$ and $\bar{t}$ such that if $\hat{t} \in[\underline{t}, \bar{t}]$, the equilibrium outcome is $\bar{a}$ win-winwin situation for both firms and the supplier (compared to the equilibrium outcome in Proposition 5). The supply chain efficiency improvement $\Delta \%$ is

$$
\Delta \%=\frac{(H-L)(\gamma-p \alpha \beta)}{p(2-2 \alpha+\alpha \beta) L+p \alpha(2-\beta) H-\gamma(H+L)} .
$$

From the firms' perspective, when the correlation between the two firms is not large, the value of transferrable capacity is high because of the high chance of earning extra profit from the transferred capacity when the reserved capacity is not utilized by the firm. Therefore, although the capacity reservation level for one firm is smaller $\left(\frac{H+L}{2}<H\right)$ while the capacity reservation price is higher $((p-w) \alpha[1+\hat{t}(1-\beta)]>$ $(p-w) \alpha)$, the firm still benefits from choosing transferrable capacity. In the win-win-win situation, we note that the supply chain efficiency is improved although the capacity reservation level is reduced, because the flexibility in utilizing the reserved capacity allows the supply chain to save some capacity installation cost with less reserved capacity.

\section{Robustness Check and Numerical Analysis}

So far we have utilized a symmetric two-point distribution of demand to derive theoretical results and generate managerial insights for analytical tractability. In this section, we perform the robustness checks with the random demands of firms $i$ and $j,\left(D_{i}, D_{j}\right)$, following a bivariate normal distribution. The marginal distribution of $D_{i}$ is normal with mean $\mu_{i}$ and standard deviation $\sigma_{i}$, and the correlation between the two demands is $\rho$. We note that the game among the three parties is complicated: the two buyers decide both capacity reservation types and levels while the supplier decides the capacity reservation prices. The interaction among the three decisions makes the theoretical analysis intractable under a bivariate normal distribution. Therefore, we numerically derive the equilibrium using bivariate normal demand distribution, and illustrate the robustness of the managerial insights obtained with the two-point distributions while exploring the impact of other factors. We then 
utilize the numerical testing beds to explore the efficiency implications of the capacity reservation contracts.

We use the following default parameters (if not changed as a variable in the analysis): the market price $p=15$, the wholesale price $w=5$, the capacity installation cost $\gamma=7$, the marginal distribution for demand $i$ is normal with mean $\mu_{1}=\mu_{2}=10$ and standard deviation $\sigma_{1}=\sigma_{2}=1$, and the demand correlation $\rho=0$.

In what follows, we first illustrate the comparison among the firms' equilibrium capacities. Then we show the impact of demand correlation, illustrate the impact of capacity transfer price on the equilibrium outcome, and show the Pareto-improvement region. After that, we illustrate the impact of demand asymmetry on the equilibrium capacity reservation levels and profits. We finally analyze the efficiency loss in the supply chain associated with capacity reservation. In addition, we have conducted the analysis regarding the equilibrium capacity reservation levels in the presence of three buying firms in Appendix C.

Comparison of equilibrium capacity. The comparison of the equilibrium capacity is provided in Figure 5 . We first notice that the equilibrium exclusive capacity $k^{e e}$ is greater than the equilibrium first-priority capacity $k^{f f}$. We then observe that as the capacity transfer price $\hat{t}$ increases, the equilibrium transferrable capacity also increases. When the transfer price $\hat{t}$ is small $(\hat{t}=0.1)$, the equilibrium transferrable capacity $k^{t t}$ is close to the equilibrium first-priority capacity $k^{f f}$. On the other hand, when the transfer price $\hat{t}$ is sufficiently large $(\hat{t}=0.9)$, the equilibrium transferrable capacity $k^{t t}$ is greater than the equilibrium exclusive capacity $k^{e e}$. These observations are consistent with the comparison between the equilibrium capacities in Propositions 1 and 7.

Impact of demand correlation. Similar to the result in Proposition 4, we observe that when the capacity reservation price is small for first-priority capacity $\left(c_{f}=3\right)$, as demand correlation increases, the freerider region shrinks as shown in Figure 6a. The freerider region shrinks because when first-priority capacity is relatively inexpensive, the benefit from choosing the more expensive exclusive capacity and forcing the other firm to build larger first-priority capacity decreases faster than the profit when both firms choose first-priority capacity, as the demand correlation increases.

However, when the capacity reservation price is high for first-priority capacity $\left(c_{f}=6\right)$, as demand correlation increases, the free-rider region first expands and then shrinks as shown in Figure 6b. This occurs because when first-priority capacity is expensive and the demand is significantly negatively correlated, the pooling benefit when both firms choose first-priority
Figure 5 Comparison of Equilibrium Capacities: $k^{e e}, \boldsymbol{k}^{t f}$, and $\boldsymbol{k}^{t t}$, When Capacity Reservation Price $c_{e}=c_{f}=c_{t}$

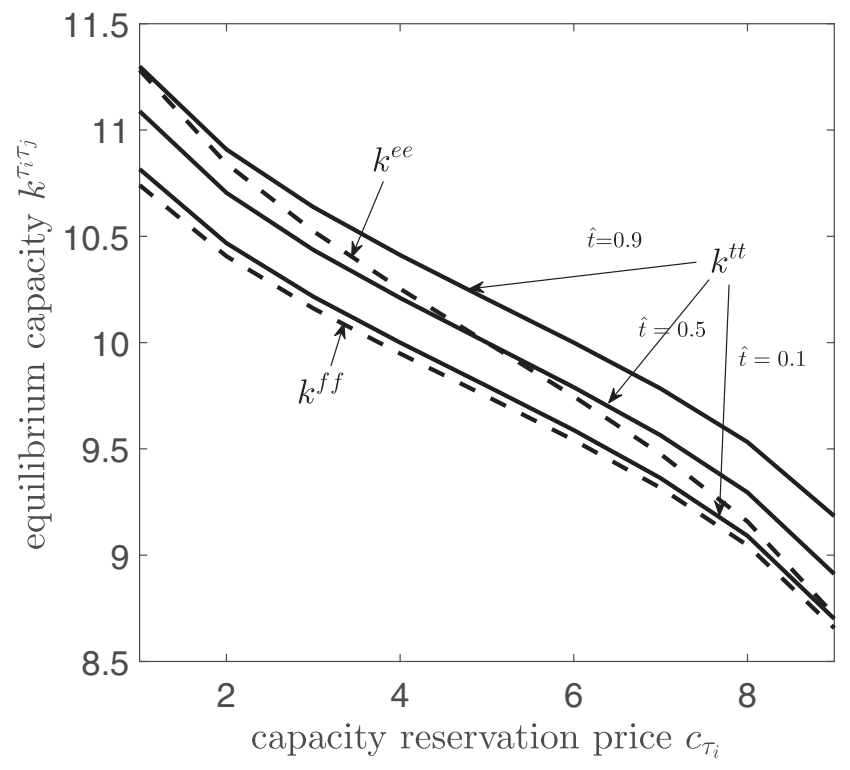

capacity significantly decreases, as the demand correlation increases. When the demand is more positively correlated, the impact is reversed and the intuition is similar to the case above.

Impact of capacity transfer price. We illustrate the Pareto-improvement region with respect to the capacity transfer price $\hat{t}$ in Figure 7 . When the capacity choices are between exclusive and first-priority capacities, both firms choosing exclusive capacity is the equilibrium, resulting in the profits of $\pi_{s}^{e e}$ and $\pi_{i}^{e e}$ in the figures. When the capacity choices are between exclusive and transferrable capacities, we observe that when $\hat{t}$ is between 0.05 and 0.49 , both firms' and supplier's profits are higher than the ones in the previous case. Therefore, when the capacity transfer price $\hat{t}$ is in the Pareto-improvement region (indicated by the gray area), all three stakeholders (one supplier and two buying firms) obtain a higher profit, resulting in a higher supply chain efficiency.

Impact of demand asymmetry. To explore the impact of demand asymmetry between the two buying firms, we consider two scenarios. In the first scenario, we fix the demand of firm 1 and change the mean of firm 2's demand. In the second scenario, we fix the demand of firm 1 and change the standard deviation of firm 2's demand. Under both scenarios, we numerically compute the supplier's equilibrium capacity reservation price, the buying firms' equilibrium capacity type and reservation level choices, as well as the equilibrium profit for both firms and the supplier. The outcomes of the two scenarios are reported in Tables 1 and 2 respectively. We note that the parameters of Setting $D$ in Table 1 and the 
Figure 6 Impact of Demand Correlation on Equilibrium Capacity Type Choices $\left(\boldsymbol{k}_{1}^{\tau_{1} \tau_{2}}, \boldsymbol{k}_{2}^{\tau_{1} \tau_{2}}\right)$

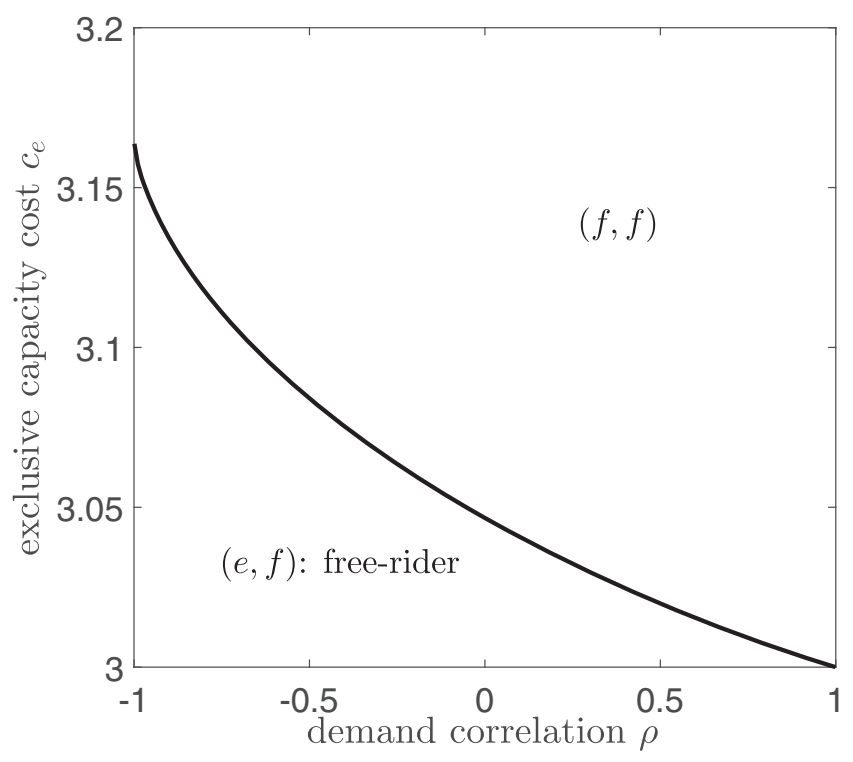

(a) first-priority capacity reservation price $c_{f}=3$

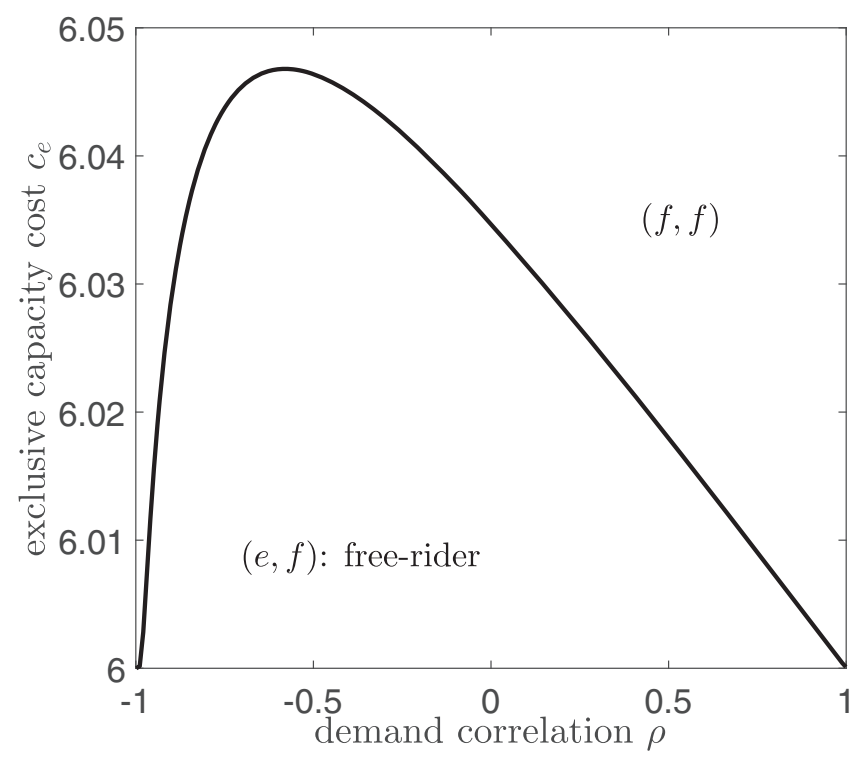

(b) first-priority capacity reservation price $c_{f}=6$ parameters of Setting $K$ in Table 2 are the same, and therefore the equilibrium outcomes are the same. For continuity of the comparison we list both scenarios in their respective tables.

We first observe from Tables 1 and 2 that under all settings, when the capacity type choices are between exclusive and first-priority capacity, both buying firms choose the exclusive capacity in equilibrium; when the capacity type choices are between exclusive and transferrable capacity, both firms choose the transferrable capacity in equilibrium; the equilibrium in the latter case results in Pareto-improvement for profits of both firms and the supplier. Thus, the insight that the transferrable capacity could result in Pareto-improvement for all three parties is still robust.

We next explain the difference on the impact of the difference in the means of demands (Table 1) and the difference in the standard deviations of demands (Table 2). As the mean of firm 2's demand increases from 7 to 13 (while fixing the mean of firm 1's demand at 10), the supplier charges higher capacity reservation prices to explore the higher demands of the firms. As a result, firm 1, whose demand remains the same, suffers from the higher capacity reservation prices, and reduces the capacity reservation quantities. Therefore, firm 1's profit decreases in the mean of firm 2's demand. On the other hand, the increased mean demand faced by firm 2 corrects the negative incentive to reserve capacity due to the higher capacity reservation prices. Therefore, firm 2 reserves a higher capacity level and the profit of firm 2 increases, as the mean of firm 2's demand increases. The supplier benefits from a larger demand of the buying firms, and therefore, the supplier's profit also increases in the mean of firm 2's demand.

As the standard deviation of firm 2's demand increases from 0.7 to 1.3 (while fixing the standard deviation of firm 1's demand at 1), the supplier reduces the capacity reservation prices. As a result, firm 1 benefits from the reduced capacity reservation prices and increases the capacity reservation quantities. Thus, firm 1's profit increases in the standard deviation of firm 2's demand. On the other hand, firm 2 reduces the capacity reservation quantities due to the increased standard deviation of its demand. However, firm 2 also significantly benefits from the lower capacity reservation prices charged by the supplier, and therefore, firm 2's profit also increases in its demand standard deviation. The supplier is hurt by the demand with a higher standard deviation of demands. Thus, the supplier's profit decreases in the standard deviation of firm 2's demand.

Efficiency loss with capacity reservation. In a centralized supply chain, both the buyers and the supplier integrate as one firm $c$ (abbreviated for "centralized"). Therefore, the firm $c$ 's profit $\pi_{c}\left(k_{c}\right)$ is as follows:

$$
\pi_{c}\left(k_{c}\right)=p E\left[\min \left\{D_{1}+D_{2}, k_{c}\right\}\right]-\gamma k_{c} .
$$

Firm $c$ should install the capacity reservation level to maximize the profit $\pi_{c}\left(k_{c}\right)$. Comparing to the case of transferrable capacity, the integrated firm does 
Figure 7 Pareto-Improvement Region (gray area) with Respect to Capacity Transfer Price $\hat{t}$

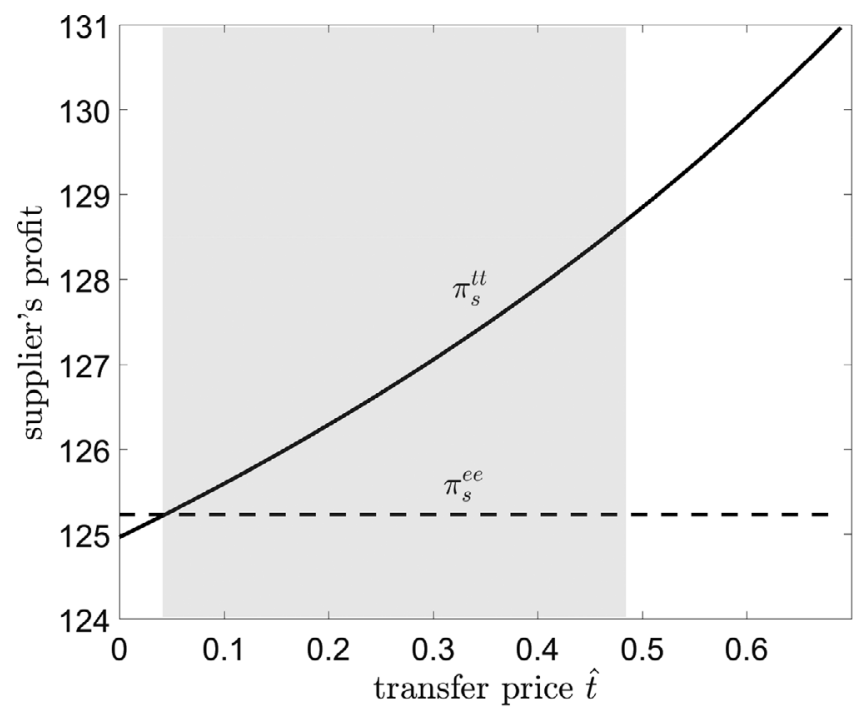

(a) supplier's profit

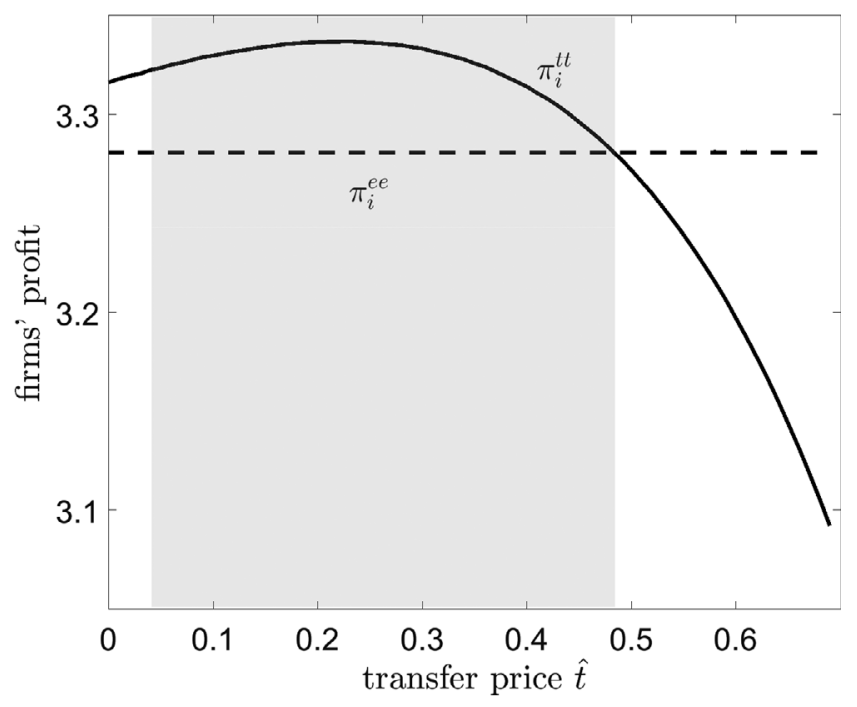

(b) buying firm's profit

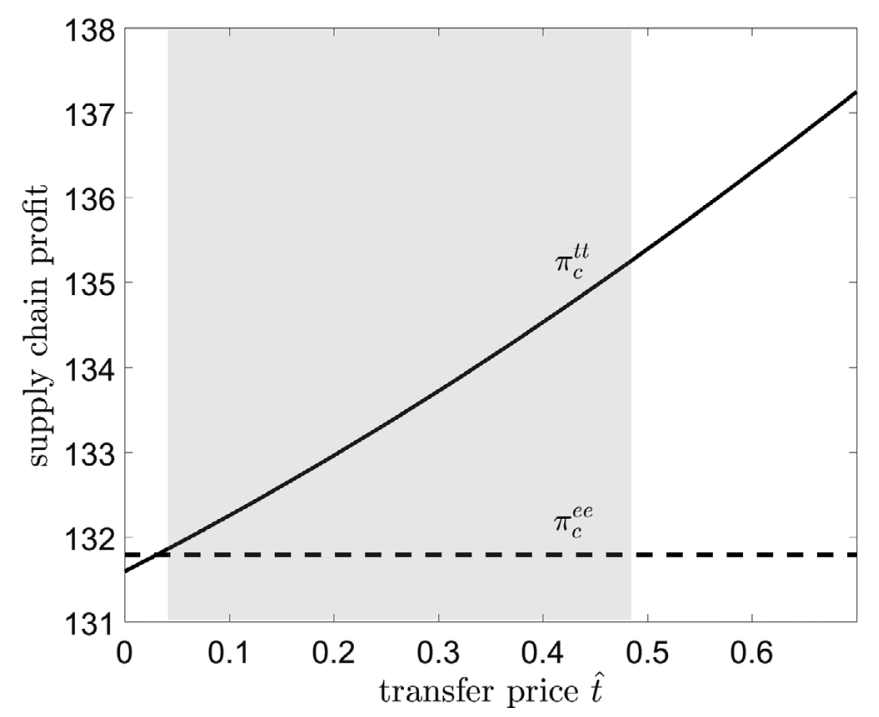

(c) supply chain's profit

not suffer from the double marginalization while maintaining the flexibility to satisfy either buyer's demand. Therefore, one may expect that the centralized capacity reservation level is higher than the one under transferrable capacity. On the other hand, comparing to exclusive capacity, while the integrated firm does not suffer from double marginalization (which should lead to a higher capacity level), it is also more flexible to utilize the installed capacity (which should lead to a lower capacity level due to demand pooling). Whether the total centralized capacity is higher or lower than the one under exclusive capacity depends on which effect is stronger. In Figure 8, we observe that the absence of double marginalization has a strong impact on the capacity decision and therefore the centralized capacity is much higher than in other cases. In addition, the higher the capacity transfer price is, the higher the total capacity is induced as both firms are willing to reserve more capacity.

We then compare the supply chain efficiency to the centralized benchmark in Figure 9. When transferrable capacity is not available, the supplier induces both firms to choose exclusive capacity; when transferrable capacity is available, the supplier induces both firms to choose transferrable capacity. We observe that the efficiency is improved under transferrable capacity than under exclusive capacity when we compare the case of $\tau_{i}=t$ to that of $\tau_{i}=e$. In addition, we observe that for given capacity installation 
Table 1 Impact of Asymmetric Mean of Demands

\begin{tabular}{|c|c|c|c|c|c|c|c|c|c|}
\hline \multirow[b]{2}{*}{ Setting } & \multirow[b]{2}{*}{$\left(\mu_{1}, \mu_{2}\right)$} & \multicolumn{4}{|c|}{$(e, f)$} & \multicolumn{4}{|c|}{$(e, t)$} \\
\hline & & $\left(\tau_{1}^{*}, \tau_{2}^{*}\right)$ & $c_{e}^{*}$ & $\left(k_{1}^{e e}, k_{2}^{e e}\right)$ & $\left(\Pi_{1}^{e e}, \Pi_{2}^{e e}, \Pi_{s}^{e e}\right)$ & $\left(\tau_{1}^{*}, \tau_{2}^{*}\right)$ & $c_{t}^{*}$ & $\left(k_{1}^{t t}, k_{2}^{t t}\right)$ & $\left(\Pi_{1}^{t t}, \Pi_{2}^{t t}, \Pi_{s}^{t t}\right)$ \\
\hline $\bar{A}$ & $(10,7)$ & $(e, e)$ & 9.49 & $(8.37,5.37)$ & $(4.08,2.54,102.62)$ & $(t, t)$ & 9.51 & $(8.45,5.45)$ & $(4.10,2.63,104.39)$ \\
\hline$B$ & $(10,8)$ & $(e, e)$ & 9.52 & $(8.33,6.33)$ & $(3.78,2.82,110.13)$ & $(t, t)$ & 9.54 & $(8.42,6.42)$ & $(3.81,2.90,111.91)$ \\
\hline C & $(10,9)$ & $(e, e)$ & 9.55 & $(8.30,7.30)$ & $(3.51,3.07,117.66)$ & $(t, t)$ & 9.57 & $(8.39,7.39)$ & $(3.56,3.13,119.47)$ \\
\hline$D$ & $(10,10)$ & $(e, e)$ & 9.58 & $(8.27,8.27)$ & $(3.28,3.28,125.23)$ & $(t, t)$ & 9.60 & $(8.36,8.36)$ & $(3.33,3.33,127.06)$ \\
\hline$E$ & $(10,11)$ & $(e, e)$ & 9.61 & $(8.24,9.24)$ & $(3.07,3.47,132.83)$ & $(t, t)$ & 9.62 & $(8.34,9.34)$ & $(3.13,3.51,134.67)$ \\
\hline$F$ & $(10,12)$ & $(e, e)$ & 9.63 & $(8.21,10.21)$ & $(2.89,3.63,140.45)$ & $(t, t)$ & 9.64 & $(8.31,10.31)$ & $(2.95,3.67,142.30)$ \\
\hline G & $(10,13)$ & $(e, e)$ & 9.65 & $(8.19,11.19)$ & $(2.72,3.77,148.09)$ & $(t, t)$ & 9.66 & $(8.29,11.29)$ & $(2.79,3.81,149.95)$ \\
\hline
\end{tabular}

Note: $(e, f)$ indicates the capacity type choices are the exclusive capacity and the first-priority capacity; $(e, t)$ indicates the capacity type choices are the exclusive capacity and the transferrable capacity.

Table 2 Impact of Asymmetric Standard Deviation of Demands

\begin{tabular}{|c|c|c|c|c|c|c|c|c|c|}
\hline \multirow[b]{2}{*}{ Setting } & \multirow[b]{2}{*}{$\left(\sigma_{1}, \sigma_{2}\right)$} & \multicolumn{4}{|c|}{$(e, f)$} & \multicolumn{4}{|c|}{$(e, t)$} \\
\hline & & $\left(\tau_{1}^{*}, \tau_{2}^{*}\right)$ & $c_{e}^{*}$ & $\left(k_{1}^{e e}, k_{2}^{e e}\right)$ & $\left(\Pi_{1}^{e e}, \Pi_{2}^{e e}, \Pi_{s}^{e e}\right)$ & $\left(\tau_{1}^{*}, \tau_{2}^{*}\right)$ & $C_{t}^{*}$ & $\left(k_{1}^{t t}, k_{2}^{t t}\right)$ & $\left(\Pi_{1}^{t t}, \Pi_{2}^{t t}, \Pi_{s}^{t t}\right)$ \\
\hline$H$ & $(1,0.7)$ & $(e, e)$ & 9.66 & $(8.17,8.72)$ & $(2.64,2.87,129.32)$ & $(t, t)$ & 9.67 & $(8.28,8.78)$ & $(2.67,2.91,130.86)$ \\
\hline I & $(1,0.8)$ & $(e, e)$ & 9.63 & $(8.21,8.57)$ & $(2.85,3.01,127.93)$ & $(t, t)$ & 9.65 & $(8.31,8.64)$ & $(2.89,3.06,129.58)$ \\
\hline$J$ & $(1,0.9)$ & $(e, e)$ & 9.61 & $(8.24,8.41)$ & $(3.06,3.15,126.57)$ & $(t, t)$ & 9.62 & $(8.34,8.50)$ & $(3.11,3.20,128.31)$ \\
\hline K & $(1,1)$ & $(e, e)$ & 9.58 & $(8.27,8.27)$ & $(3.28,3.28,125.23)$ & $(t, t)$ & 9.60 & $(8.36,8.36)$ & $(3.33,3.33,127.06)$ \\
\hline$L$ & $(1,1.1)$ & $(e, e)$ & 9.56 & $(8.30,8.13)$ & $(3.50,3.41,123.93)$ & $(t, t)$ & 9.57 & $(8.39,8.23)$ & $(3.56,3.46,125.82)$ \\
\hline$M$ & $(1,1.2)$ & $(e, e)$ & 9.53 & $(8.33,7.99)$ & $(3.73,3.53,122.64)$ & $(t, t)$ & 9.55 & $(8.41,8.10)$ & $(3.79,3.58,124.60)$ \\
\hline$N$ & $(1,1.3)$ & $(e, e)$ & 9.50 & $(8.35,7.86)$ & $(3.96,3.65,121.39)$ & $(t, t)$ & 9.52 & $(8.43,7.98)$ & $(4.02,3.70,123.39)$ \\
\hline
\end{tabular}

Note: $(e, f)$ indicates the capacity type choices are the exclusive capacity and the first-priority capacity; $(e, t)$ indicates the capacity type choices are the exclusive capacity and the transferrable capacity.

cost $\gamma$, the efficiency loss decreases as the capacity transfer price $\hat{t}$ increases, which is consistent with the observation on the equilibrium capacity - the higher the capacity transfer price, the closer the equilibrium capacity is to the centralized capacity. These observations attest to the benefit of transferrable capacity to

Figure 8 Equilibrium Capacity Comparison

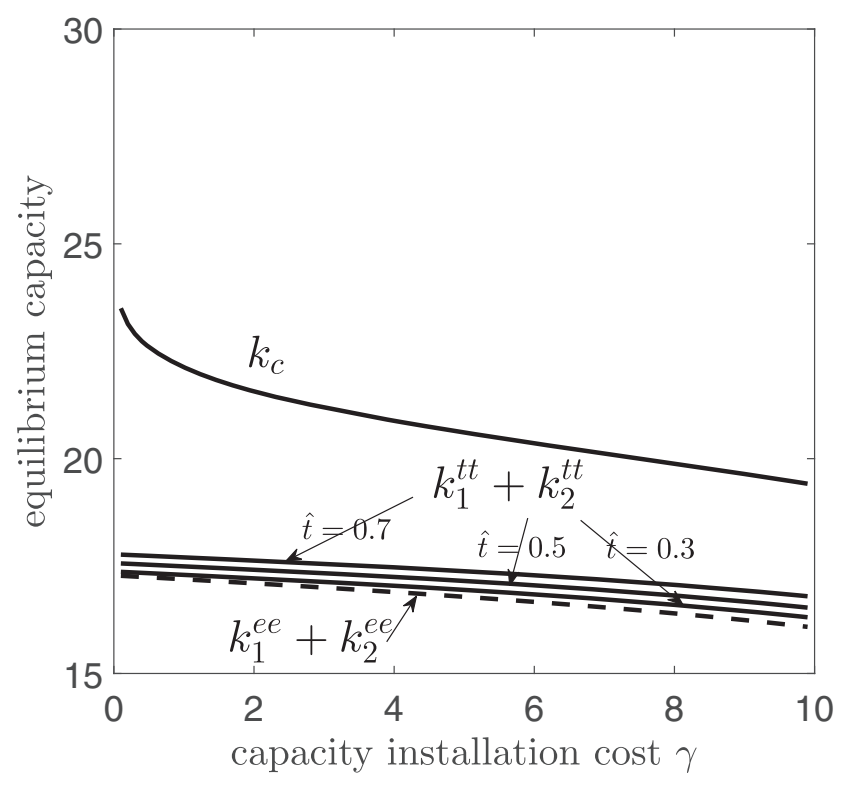

improve the supply chain efficiency over exclusive capacity.

\section{Concluding Remarks}

We analyze a capacity reservation problem when multiple firms order from a common supplier. When the firms choose between exclusive and first-priority reservations, we identify three equilibria, and show that two factors-capacity reservation prices and demand correlation-critically affect which equilibrium (and what capacity reservation level) arises. As the cost of reserving capacity exclusively increases, the equilibrium shifts from both firms choosing exclusive capacity, to one firm choosing exclusive capacity and the other firm choosing first-priority capacity, to both firms choosing first-priority capacity. As demand correlation decreases, contrary to the conventional wisdom that the firms should be more likely to choose first-priority capacity for resource pooling (which is more beneficial when the demand correlation is low or negative), we find that firms are less likely to reserve first-priority capacity-that is, the region in which at least one firm prefers to reserve capacity exclusively increases.

We identify two cases where the equilibrium reservation can be inefficient for the buying firms. When the price of exclusive capacity is slightly higher than 
Figure 9 Supply Chain Efficiency Loss

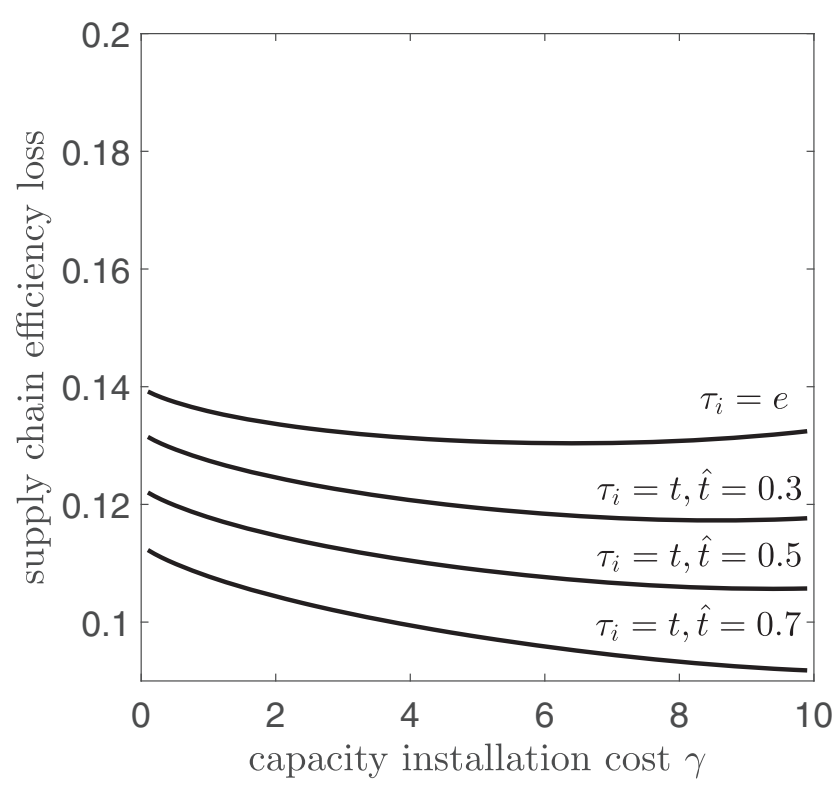

Note. The curve $\tau_{i}=e$ compares the scenario where both firms are induced to choose exclusive capacity (Proposition 5) to the centralized benchmark (the difference between the two profits divided by the profit in the centralized benchmark). The curves $\tau_{i}=t$ compare the scenario where both firms are induced to choose transferrable capacity with the capacity transfer price $\hat{t}$ to the centralized benchmark.

the price of first-priority capacity, a free-rider equilibrium arises in which one firm reserves large firstpriority capacity and the other firm reserves small exclusive capacity. In this scenario, the firm reserving exclusive capacity would have been better off if it had reserved the same amount of first-priority capacity. However, the firm needs to reserve the more expensive exclusive capacity in order to induce the other firm to reserve a large amount of first-priority capacity. On the other hand, if the price of exclusive capacity is the same as first-priority capacity, firms may reserve a large exclusive capacity instead of pooling the capacity by choosing first-priority reservation, resulting in a prisoner's dilemma. In this case, the firms would have been better off if both firms had reserved less capacity under first-priority reservation and shared their leftovers. Therefore, demanding the exclusive right to use the capacity does not necessarily serve the buying firm's best interests. Once again, demand correlation plays a critical role: The adverse outcomes vanish as the demand correlation increases.

When the supplier strategically sets the capacity reservation prices, it induced the firms to reserve a large amount of exclusive capacity, resulting in both firms being trapped in the prisoner's dilemma. Although this seems to be the best scenario for the supplier, we find that an even better arrangement is possible which benefits all three parties of the supply chain - the supplier and both buyers, if the buyers are allowed to trade their leftover capacity with each other at a capacity transfer price. This transferrable capacity arrangement, which is a modified first-priority capacity with a capacity transfer price, allows the firms to possibly earn profits from their leftover capacity and thus results in a higher valuation of the reserved capacity. On the other hand, the supplier is able to charge a higher capacity reservation price because of the firms' higher valuations for capacity. When the demand correlation is low enough, the capacity transfer price may lead to a win-win-win equilibrium outcome to both the supplier and the buying firms.

Our study suggests several future research opportunities. At a more general level, given the increasing trend of decentralized supply networks, one potential opportunity is to consider a multi-tier supply chain in which the lower-tier buying firms may also reserve capacity or conduct other supplier development activities at upper-tier sub-suppliers who supply to the immediate suppliers of these buying firms. Also, under such multi-tier supply chain structure, what might happen if the buying firms acquire a supplier or a sub-supplier? How will information asymmetry regarding the supplier's cost or the buyer's demand affect the decisions in such a supply network? We believe that such scenarios will provide several fruitful research opportunities in this area.

\section{Acknowledgment}

The authors thank the Department Editor, the anonymous Senior Editor, and two anonymous referees for their comments and suggestions that have significantly improved this study.

\section{Notes}

${ }^{1}$ Cosmax is a leading ODM (Original Design Manufacturer) of beauty and cosmetic products based in South Korea.

${ }^{2}$ Another reason why the exclusive reservation is more costly than first-priority reservation from the buying firms' perspective is that implementing exclusive capacity often requires effort on the part of the buying firms and the implementation cost can be proportionate to the reserved capacity, e.g., installing monitoring devices such as counters on each reserved machine. In our study, we focus on the fact that the supplier may have incentive to offer a discount, since the implementation cost associated with the exclusive capacity (such as the cost to install counters on each machine) is relatively small compared to the capacity reservation cost.

${ }^{3} \mathrm{~A}$ random variable $X$ is larger than a random variable $Y$ in the usual stochastic sense, that is, $X \geq{ }_{s t} Y$, if $P(X \leq x) \leq P(Y \leq x)$ for any given $x \in(-\infty, \infty)$. 
${ }^{4}$ We note first-priority capacity is a special case of transferrable capacity when the transfer price is 0 .

\section{References}

Arya, A., B. Mittendorf, D. E. M. Sappington. 2008. The makeor-buy decision in the presence of a rival: Strategic outsourcing to a common supplier. Management Sci. 54(10): 1747-1758.

Babich, V. 2010. Independence of capacity ordering and financial subsidies to risky suppliers. Manuf. Serv. Oper. Manag. 12(4): 583-607.

Cachon, G. P., P. T. Harker. 2002. Competition and outsourcing with scale economies. Management Sci. 48(10): 1314-1333.

Cachon, G. P., M. A. Lariviere. 1999. Capacity choice and allocation: Strategic behavior and supply chain performance. Management Sci. 45(8): 1091-1108.

Dixit, A. 1980. The role of investment in entry-deterrence. Econ. J. 90(357): 95-106.

Economist. 1996. Asian semiconductors: Saving chips from market dips. January 20, p. 63.

Goyal, M., S. Netessine. 2007. Strategic technology choice and capacity investment under demand uncertainty. Management Sci. 53(2): 192-207.

Iyer, A. V., L. B. Schwarz, S. A. Zenios. 2005. A principal-agent model for product specification and production. Management Sci. 51(1): 106-119.

Jin, Y., Q. Hu, S. W. Kim, S. X. Zhou. 2019. Supplier development and integration in competitive supply chains. Prod. Oper. Manag. 28(5): 1256-1271.

Kemahlığlu-Ziya, E. 2015. Contracting for capacity under renegotiation: Partner preferences and the value of anticipating renegotiation. Prod. Oper. Manag. 24(2): 237-252.

LaPedus, M. 1995. Two in Taiwan lay new plans. Electronic Buyers' News, August 28, p. 10.

Li, C. 2013. Sourcing for supplier effort and competition: Design of the supply base and pricing mechanism. Management Sci. 59(6): 1389-1406.

Li, C., Z. Wan. 2016. Supplier competition and cost improvement. Management Sci. 63(8): 2460-2477.

Li, L., I. Duenyas, S. M. R. Iravani. 2011. Capacity option transfer rights: Do they benefit suppliers? Working paper, Northwestern University, Evanston, IL.

Plambeck, E. L., T. A. Taylor. 2005. Sell the plant? The impact of contract manufacturing on innovation, capacity, and profitability. Management Sci. 51(1): 133-150.

Plambeck, E. L., T. A. Taylor. 2007. Implications of renegotiation for optimal contract flexibility and investment. Management Sci. 53(12): 1872-1886.
Qi, A., H. S. Ahn, A. Sinha. 2015. Investing in a shared supplier in a competitive market: Stochastic capacity case. Prod. Oper. Manag. 24(10): 1537-1551.

Roels, G., C. S. Tang. 2017. Win-win capacity allocation contracts in coproduction and codistribution alliances. Management Sci. 63(3): 861-881.

Simchi-Levi, D., P. Kaminsky, E. Simchi-Levi. 2008. Designing and Managing the Supply Chain: Concepts, Strategies, and Case Studies. McGraw-Hill Higher Education (McGraw-Hill/Irwin), ISBN 9780072982398. Available at https://books.google.com/ books?id=qZsbnwEACAAJ.

Taylor, T. A., E. L. Plambeck. 2007. Supply chain relationships and contracts: The impact of repeated interaction on capacity investment and procurement. Management Sci. 53(10): 1577-1593.

Ülkü, S., L. B. Toktay, E. Yücesan. 2005. The impact of outsourced manufacturing on timing of entry in uncertain markets. Prod. Oper. Manag. 14(3): 301-314.

Ülkü, S., L. B. Toktay, E. Yücesan. 2007. Risk ownership in contract manufacturing. Manuf. Serv. Oper. Manag. 9(3): 225-241.

Van Mieghem, J. A. 2003. Capacity management, investment, and hedging: Review and recent developments. Manuf. Serv. Oper. Manag. 5(4): 269-302.

Wadecki, A. A., V. Babich, O. Q. Wu. 2012. Manufacturer competition and subsidies to suppliers. Supply Chain Disrup. (Springer) 10: 141-163.

Wang, Y., W. Gilland, B. Tomlin. 2010. Mitigating supply risk: Dual sourcing or process improvement? Manuf. Serv. Oper. Manag. 12(3): 489-510.

Wang, Y., Y. Xiao, N. Yang. 2014. Improving reliability of a shared supplier with competition and spillovers. Eur. J. Oper. Res. 236(2): 499-510.

Wu, S. D., M. Erkoc, S. Karabuk. 2005. Managing capacity in the high-tech industry: A review of literature. Eng. Econ. 50(2): 125-158.

Yang, Z., G. Aydin, V. Babich, D. Beil. 2009. Supply disruptions, asymmetric information, and a backup production option. Management Sci. 55(2): 192-209.

Zhu, K., R. Q. Zhang, F. Tsung. 2007. Pushing quality improvement along supply chains. Management Sci. 53(3): 421-436.

\section{Supporting Information}

Additional supporting information may be found online in the Supporting Information section at the end of the article.

Appendix A: Proof of Results in Sections 3 and 4.

Appendix B: Proof of Results in Section 5.

Appendix C: Additional Analysis with Three Buying Firms. 